Review

\title{
Amino Acid Sensing and Assimilation by the Fungal Pathogen Candida albicans in the Human Host
}

\author{
Fitz Gerald S. Silao (1) and Per O. Ljungdahl * \\ Department of Molecular Biosciences, Wenner-Gren Institute, SciLifeLab, Stockholm University, \\ 11419 Stockholm, Sweden; fitzgerald.silao@scilifelab.se \\ * Correspondence: per.ljungdahl@scilifelab.se
}

check for updates

Citation: Silao, F.G.S.; Ljungdahl, P.O Amino Acid Sensing and Assimilation by the Fungal Pathogen Candida albicans in the Human Host. Pathogens 2022, 11, 5. https:// doi.org/10.3390/pathogens11010005

Academic Editor:

Jonathan Richardson

Received: 17 November 2021

Accepted: 19 December 2021

Published: 22 December 2021

Publisher's Note: MDPI stays neutral with regard to jurisdictional claims in published maps and institutional affiliations.

Copyright: (C) 2021 by the authors. Licensee MDPI, Basel, Switzerland. This article is an open access article distributed under the terms and conditions of the Creative Commons Attribution (CC BY) license (https:// creativecommons.org/licenses/by/ $4.0 /)$
Abstract: Nutrient uptake is essential for cellular life and the capacity to perceive extracellular nutrients is critical for coordinating their uptake and metabolism. Commensal fungal pathogens, e.g., Candida albicans, have evolved in close association with human hosts and are well-adapted to using diverse nutrients found in discrete host niches. Human cells that cannot synthesize all amino acids require the uptake of the "essential amino acids" to remain viable. Consistently, high levels of amino acids circulate in the blood. Host proteins are rich sources of amino acids but their use depends on proteases to cleave them into smaller peptides and free amino acids. C. albicans responds to extracellular amino acids by pleiotropically enhancing their uptake and derive energy from their catabolism to power opportunistic virulent growth. Studies using Saccharomyces cerevisiae have established paradigms to understand metabolic processes in C. albicans; however, fundamental differences exist. The advent of CRISPR/Cas9-based methods facilitate genetic analysis in C. albicans, and state-of-the-art molecular biological techniques are being applied to directly examine growth requirements in vivo and in situ in infected hosts. The combination of divergent approaches can illuminate the biological roles of individual cellular components. Here we discuss recent findings regarding nutrient sensing with a focus on amino acid uptake and metabolism, processes that underlie the virulence of $C$. albicans.

Keywords: Candida albicans; human fungal pathogen; nutrient sensing; amino acid metabolism; proline catabolism; mitochondria; SPS-sensor; nitrogen catabolite repression; glucose repression

\section{Introduction}

All organisms require nutrients to live, grow and successfully reproduce. The ability of an organism to assimilate nutrients in a given ecological niche is dependent on its ability to sense and respond to the availability of nutrients and on intrinsic cellular properties. Defining the key signaling events activated by nutrient sensing systems and the metabolic capacities of an organism provides a compelling description that reflects the organism's role in the niche. For opportunistic human pathogens, acquiring nutrients to support commensal or pathogenic growth is not a trivial task as the availability of key nutrients is dependent on several extrinsic host-specific factors. Such factors include host defense activities that often are linked to substantial and rapid changes in biophysical parameters, e.g., extracellular $\mathrm{pH}$ and the generation of reactive oxygen species (ROS), different nutrient and metabolic activities of host tissues at sites of fungal cell colonization, and the presence of competing microorganisms.

Of the fungal pathogens capable of infecting humans, Candida albicans is considered to be the most important, and arguably the most successful. C. albicans is a natural commensal of humans, capable of colonizing virtually all anatomical sites (Figure 1). This fungus can switch from harmless commensal to pathogenic growth and thereby cause a spectrum of pathologies, ranging from mucosal to life-threatening systemic infections, collectively termed candidiasis. It is imperative to distinguish the difference between commensal and invasive virulent growth; invasion is distinct from superficial colonization as the 
former is accompanied by inflammatory signals, resulting from the activated immune response. Clinical cases presenting C. albicans infections of the urogenital tract [1-8], kidney $[1,7,9-13]$, liver $[14,15]$, lungs [16-18], spleen [19,20] and even the heart [21-26] have been reported. In rare cases, mostly in neonates, C. albicans can traverse the bloodbrain barrier, resulting in infections of the brain [27-30]. These observations indicate that C. albicans can successfully establish and grow in different host niches. Consequently, C. albicans must possess the means to successfully adapt in order to obtain and use a wide range of host-derived nutrients. Given their opportunistic character, the question remains open as to how $C$. albicans cells fine-tune their nutrient acquisition machineries to support commensal and pathogenic growth under apparently disparate environmental conditions.

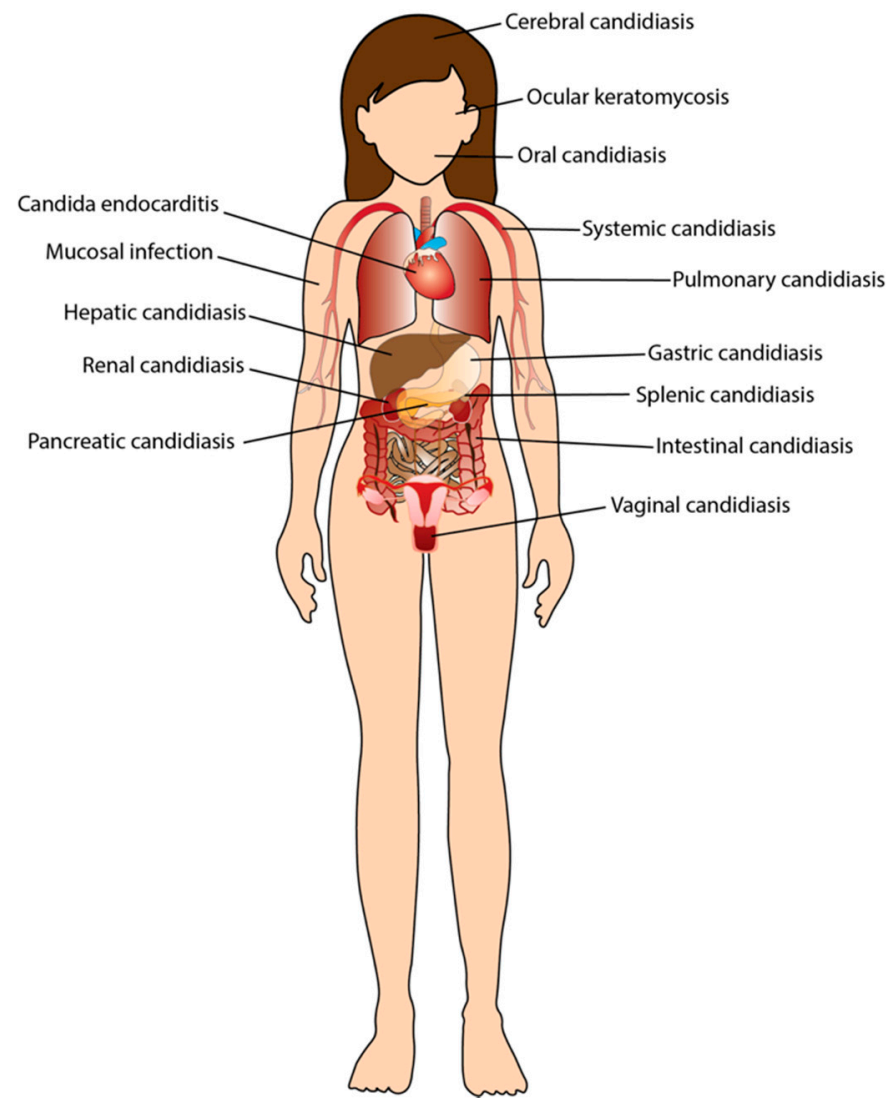

Figure 1. C. albicans can infect virtually all anatomical sites in the body. Infections can either be superficial, mainly affecting the skin or mucous membrane, or invasive, involving fungal entry into the blood (candidemia) and dissemination to other internal organs. Disseminated growth happens when C. albicans, colonizing an anatomical site (usually the gut), catheters or other medical implants, enter the blood and then disseminate to other organs such as the lungs (pulmonary), liver (hepatic), spleen (splenic), pancreas (pancreatic) and kidney (renal). These infections can be localized or can re-enter the bloodstream again, allowing them to reach additional anatomical sites, and in rare cases the brain (cerebral). C. albicans in the blood can enter the urine via the kidney, resulting in candiduria (yeast in the urine). Other complications of Candida infections include the appearance of fungus balls in certain sites, resulting in obstruction in these areas and the formation of abscesses. In women, vaginal candidiasis is an important concern since the vagina serves as a main reservoir for C. albicans. In addition, infection of the genitourinary tract is more often diagnosed in women than in men due to anatomical structural differences such as a shorter urethra and the close proximity of the vagina and anus.

C. albicans requires a source of nitrogen to synthesize proteins needed to carry out necessary cellular functions and to generate nucleotides for DNA and RNA synthesis. There is a plethora of nitrogen sources that $C$. albicans can theoretically utilize in the host, 
for example, amino acids, urea, peptides, proteins and N-acetyl glucosamine (GlcNAc) and even ammonia. Of the nitrogen sources available in the host, amino acids are preferred as they can be easily assimilated and used as both nitrogen and carbon sources [31,32]. Most of the current understanding of nutrient assimilation in C. albicans is inferred from extensive studies in the non-pathogenic yeast Saccharomyces cerevisiae. However, although many of the regulatory mechanisms operating between the two species are conserved, it is becoming clear that substantial differences exist, likely reflecting the different environments in which these fungi evolved. Although $S$. cerevisiae is readily found freely in nature, C. albicans has evolved in close association with mammalian hosts as a commensal. Furthermore, although S. cerevisiae prioritizes the ability to ferment sugar even in the presence of oxygen, $C$. albicans relies on mitochondrial oxidative phosphorylation to generate the energy necessary to survive in hosts. Aside from being able to thrive better at higher temperatures, i.e., $37^{\circ} \mathrm{C}$, a striking and important difference between $C$. albicans and S. cerevisiae is that C. albicans possesses mitochondria with all four proton-pumping and energy-conserving complexes of the respiratory chain, including NADH dehydrogenase (Complex I). In S. cerevisiae mitochondria, NADH is oxidized by matrix NADH dehydrogenases that are not coupled to energy-conserving proton-pumping mechanisms; hence, the oxidation of NADH in yeast does not directly contribute to ATP production [33].

The clear differences in metabolism between the established yeast model and the fungal pathogen $C$. albicans need to be considered when analyzing its virulence properties. In this review we focus on amino acid sensing and metabolism with an emphasis on proline catabolism. We begin by introducing some basic concepts regarding nitrogen source utilization and assimilation and then present a more focused discussion regarding amino acid metabolism, the generation of ammonia and associated consequences, and the central role of mitochondria in the production of energy for virulent growth.

\section{Amino Acids as Nitrogen Sources in Host Environments}

As an opportunistic pathogen, C. albicans can sense a multitude of environmental signals, including changes in the availability of diverse nitrogen sources, including amino acids. The signaling pathways that are induced regulate the activity of downstream effector transcription factors that engage programs of gene expression, some that are required for virulent growth (reviewed in [34,35]). A limited number of amino acid sensors have been characterized in C. albicans (Figure 2), the best understood being the plasma membrane-localized SPS sensor of extracellular amino acids [36-38]. Strains lacking a functional SPS sensor have a diminished capacity to take up amino acids, do not filament in the presence of serum and are less virulent during systemic infection in mice. These results provide a clear example of how an ordinary basic physiological process, such as nitrogen (amino acid) acquisition, can become an "accidental" but important virulence trait of an opportunistic human pathogen. Additional sensors of external amino acids in C. albicans have been reported, such as Gpr1, a G-protein-coupled receptor proposed to sense methionine [39], and Gap2, a general amino acid transporter that is the functional ortholog of Gap1 in S. cerevisiae (ScGap1) that could function as a transceptor [40]. Proteins that sense the availability of other well-characterized nitrogen sources, e.g., Mep2 that responds to ammonium [41], can also provide important regulatory signals governing amino acid use. Although $C$. albicans cells have been shown to respond to the presence of GlcNAc [42,43] and urea [44], active sensing mechanisms for these nitrogen sources have not been described. Nitrogen-containing compounds (amino acids) are taken up from the extracellular environment through a number of distinct transporters localized at the plasma membrane (Figure 2). Activation of the SPS sensor enhances the capacity of cells to take up and assimilate diverse nitrogen substances. This is accomplished as the signals derived from the activated SPS sensor induce the expression of several genes encoding amino acid permeases, secreted aspartyl protease $S A P 2$, peptide and oligopeptide transport proteins $[36,45,46]$. 


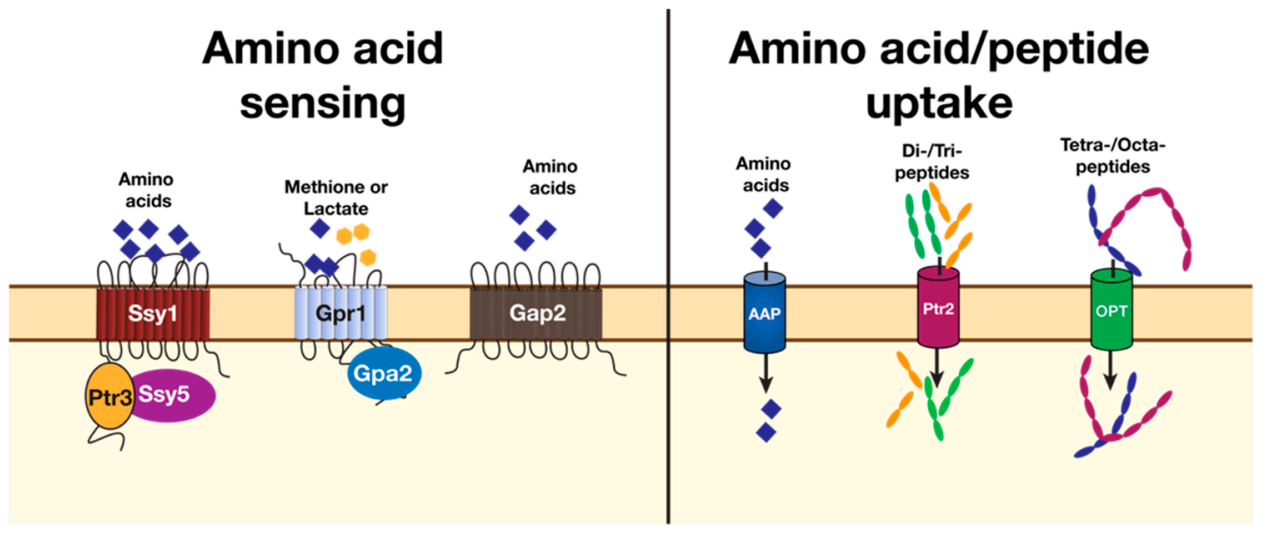

Figure 2. Amino acid sensors and transporters localized at the plasma membrane of C. albicans. (Left) the SPS sensor responds to the presence of extracellular amino acids. The main SPS sensor is composed of Ssy1, a plasma membrane-bound receptor homologous to amino acid permeases but without a capacity to transport amino acids; Ptr3, a scaffold protein that mediates intracomplex protein-protein interactions; and Ssy5, an endoprotease that proteolytically activates downstream transcription factors. The G-protein-coupled receptor 1 (Gpr1), together with intracellular cognate protein Gpa2, has been implicated in both amino acid (methionine) and lactate sensing. Gap2 is an ortholog of S. cerevisiae Gap1, which is thought to function as a transceptor, i.e., a functional transporter capable of initiating downstream signaling events independently of transport. (Right) uptake of extracellular amino acids is facilitated by a number of genetically distinct amino acid permeases (AAP) that have either broad or narrow substrate specificities. Amino acids can also enter the cell as oligopeptides taken up by Ptr2 for di-/tri-peptides, or a family of oligopeptide transporters (OPT) for oligopeptides comprising between 4 and 8 residues.

\section{Nitrogen Catabolite Repression (NCR)}

In addition to sensing the availability of extracellular sources of nitrogen, yeast cells can gauge the quality of internalized sources of nitrogen and respond appropriately to adjust metabolism. Nitrogen catabolite repression (NCR) is a supra-pathway that controls nitrogen source utilization through the repression of genes required for the utilization of secondary nitrogen sources when preferred ones are available. Most of the assumptions with respect to NCR in C. albicans are derived from extensive studies examining NCR in S. cerevisiae. Understanding the differences between these organisms is essential to accurately describing the hierarchy of nitrogen source assimilation and use by $C$. albicans during pathogenic growth.

In S. cerevisiae, NCR is controlled by four GATA transcription factors: Gln3, Gat1, Dal80 and Gzf3, all of which possess zinc-finger DNA-binding motifs that recognize a conserved GATAAG consensus sequence present in the promoters of target genes (reviewed in [47]) (Figure 3). Gln3 and Gat1 act as positive regulators of gene expression, whereas Dal80 and Gzf3 act in a negative manner to repress target gene expression. The ability of the GATA factors to compete for binding GATAAG sequences is influenced by nitrogen source availability and is even modulated by events within the nucleus [48,49]. In the presence of preferred nitrogen sources, such as ammonium and certain amino acids, Gln3 and Gat1 are tethered in the cytosol, restricting their translocation into the nucleus. For Gln3, nuclear exclusion is maintained by binding to the phosphorylated species of its interacting partner, Ure2. Gln3 and likely Gat1 can be phosphorylated, but the phosphorylation status of Gln3 does not affect its capacity to bind Ure2. Gln3 targets to and is retained in the nucleus in cells carrying deletion or mutationally inactivated alleles of Ure2, resulting in the constitutive expression of NCR-sensitive genes. Unlike Gln3, Gat1 is not entirely dependent on Ure2 for retention in the cytosol, and therefore other regulatory components apparently contribute to controlling Gat1 movement and inducing activity. Contrary to Gln3 and Gat1, Dal80 and Gzf3 are constitutively localized in the nucleus. Furthermore, in contrast to GLN3, GAT1, GZF3 and DAL80 are expressed under the control of promoters containing multiple 
GATAAG sequences, placing their expression under NCR [50-53]. Consequently, these factors participate in regulating each other's expression (cross-regulation) and in certain instances exhibit partial autogenous regulation [48,52-54] (Figure 3).

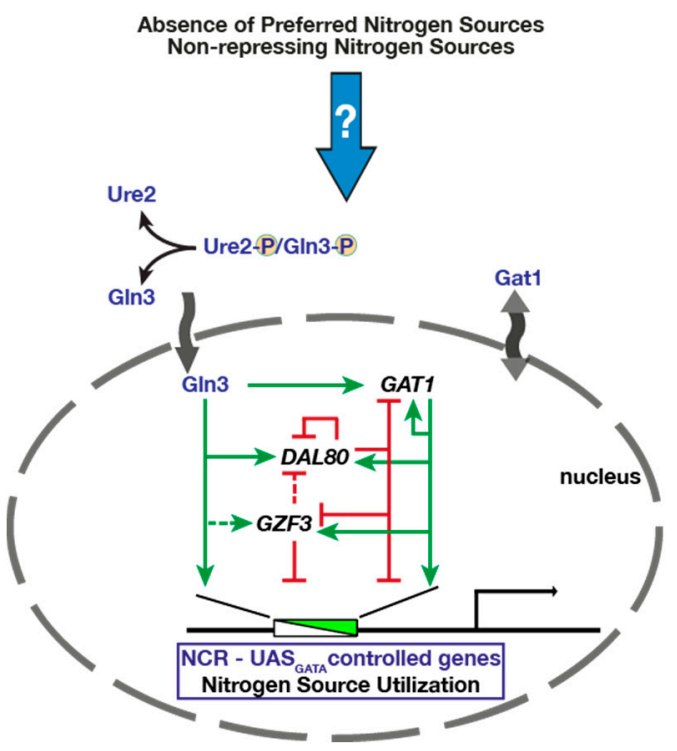

Figure 3. Schematic diagram of nitrogen catabolite repression (NCR) in yeast (adapted from Ljungdahl and Daignan-Fornier, 2012 [47]). Gln3 and Gat1 are two positive GATA effectors of NCR that are normally excluded from the nucleus under preferred nitrogen replete conditions. Nuclear exclusion is thought to occur via the interaction of Gln3 with the phosphorylated version of the Ure2 protein.

NCR has been described in C. albicans; however, the information available is limited to studies using strains lacking Gln3 and/or Gat1 [55-57]. Strains lacking either or both of these GATA transcription factors are unable to efficiently utilize a number of alternative nitrogen sources. This has been shown to be linked to the lack of derepression of genes necessary for their catabolism. Results from the Fonzi laboratory have shown that Gln3 and Gat1 appear to exert both specific and overlapping functions, depending on the available nitrogen sources [56]. Certain amino acids traditionally classified as poor, such as proline in $S$. cerevisiae $[47,58]$, are readily utilized by C. albicans lacking Gln3 and Gat1, clearly indicating that proline utilization is not subject to tight NCR control [56]. Consistently, recent work in our group and others have shown that enzymes of the proline catabolic pathway (e.g., Put1 and Put2) can be induced in the presence of preferred nitrogen sources (e.g., ammonium or amino acids) [59-61] and even in a strain lacking Gln3 and Gat1 [59]. In addition, the gene encoding glutamate dehydrogenase (GDH2), a key player in central nitrogen metabolism, is robustly expressed when there is an abundance of preferred nitrogen sources such as ammonium and amino acids, indicating that its expression is independent of NCR [61]. This latter finding is in striking contrast to S. cerevisiae, with its GDH2 subject to tight NCR control (reviewed in [47]).

These clear differences between C. albicans and S. cerevisiae are not trivial, and clearly reflect divergent evolutionary trajectories and the need for $C$. albicans to rapidly respond to distinct host environments. For example, as C. albicans cells breach epithelial barriers and reach the blood, they are exposed to high concentrations of amino acids, a condition that likely represses NCR-controlled genes, including those required for the assimilation of nitrogen derived from the degradation of host proteins. The transcription factor STP1 is NCR-controlled and under these conditions is not expressed, which limits the expression of the Stp1-dependent secreted protease Sap2 and oligopeptide transporters. 


\section{Extracellular Amino Acid Sensing and Uptake-The SPS Sensing System}

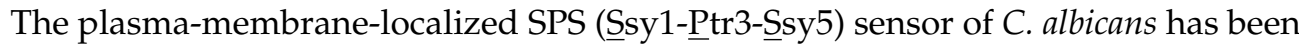
characterized [36,38,59,62]. The SPS sensor enables cells to sense and respond to the presence of extracellular amino acids (Figure 4). Again, progress has largely been guided by ongoing studies using S. cerevisiae as a model. In S. cerevisiae, the SPS signaling pathway controls the expression of a distinct set of amino acid permease (AAP) genes encoding transporters catalyzing proton-driven amino acid uptake. Two homologous effector transcription factors, Stp1 and Stp2, are synthesized as inactive precursors that localize to the cytoplasm due to $\mathrm{N}$-terminal regulatory domains. The regulatory domains possess cytoplasmic retention and nuclear degron motifs, both of which are required to maintain the "off-state" of SPS-sensor-regulated gene expression. The cytoplasmic retention motifs prevent these factors from efficiently entering the nucleus, and the degron motif targets the low levels of full-length Stp1 and Stp2 that escape cytoplasmic retention for degradation by means of a novel inner-nuclear-membrane-associated degradation (INMAD) pathway. The INMAD pathway is defined by the E3 ubiquitin ligase Asi complex (Asi1-Asi2-Asi3) [63-65]. Extracellular amino acids activate the SPS sensor by binding to the receptor component Ssy1, which undergoes a conformational change that activates the Ssy5 protease in a Ptr3dependent manner: Ptr3 functions as a scaffold that mediates intracomplex protein-protein interactions. Activated Ssy5 cleaves the N-terminal regulatory domains of Stp1 and Stp2, a processing event that enables the cleaved factors, lacking cytoplasmic retention and degron motifs, to efficiently translocate to the nucleus and bind to upstream activating sequences (UASaa) in the promoters of AAP genes. AAPs are co-translationally inserted into the endoplasmic reticulum (ER) membrane, contiguous with the outer nuclear membrane. The movement of AAPs to the PM requires the ER membrane-localized chaperone Shr3, which facilitates their folding and packaging into ER-derived secretory vesicles, a requisite for their functional expression $[66,67]$. The SPS sensing system enables amino acids to induce their own uptake.

Orthologs of the SPS sensing system are present in C. albicans ([36-38,59,62]; reviewed in [35]) (Figure 4). There is, however, a major difference. In contrast to S. cerevisiae, Stp1 and Stp2 in C. albicans activate different sets of genes that express proteins facilitating the assimilation of distinct external nitrogen sources [36,62]. Stp1 regulates the expression of SAP2, encoding the major and broad-spectrum secreted aspartyl proteinase (Sap) and multiple oligopeptide transporters (Opts) [36]. STP1 expression is subject to NCR and controlled by the GATA transcription factors Gln3 and Gat1 ([68], reviewed in [69]). Accordingly, STP1 expression is repressed when preferred nitrogen sources, i.e., ammonium sulfate and amino acids, are available and is derepressed when these nitrogen sources become limiting or absent. STP2 is constitutively expressed and functions analogously to Stp1/Stp2 in S. cerevisiae and derepresses the expression of multiple amino acid permeases. C. albicans strains lacking either Ssy1 or Csh3, the latter an ortholog of yeast Shr3, fail to efficiently respond to the presence of extracellular amino acids and have impaired an capacity to filament in amino acid-based media $[37,38]$. Not all amino acids activate the SPS sensor, as can be observed by monitoring the proteolytic processing of Stp2 [36,59]. The capacity to activate the sensor and induce Stp2 processing is limited to a subset of amino acids; the presence of glutamine and arginine leads to robust SPS sensor activation. Stp2 processing is observed 5 min post-induction, indicating that the SPS sensing system rapidly responds to the presence of extracellular amino acids. 


\section{OFF}
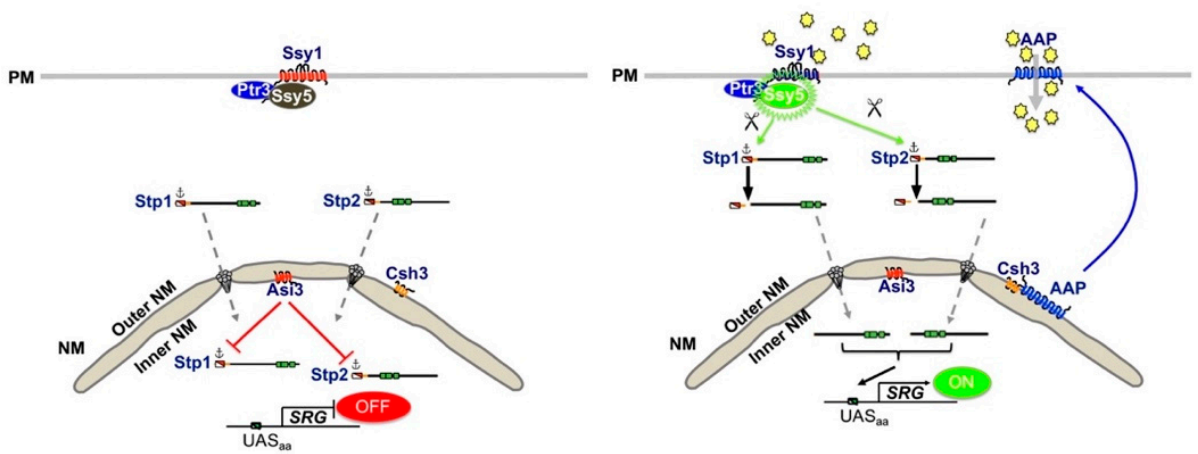

Figure 4. The SPS sensing system of $C$. albicans. Ssy1 is the primary amino acid sensor that functions with the scaffold protein Ptr3 and the protease Ssy5 as a multimeric receptor complex. Stp1 and Stp2 are the effector transcription factors of this pathway. ((Left panel), OFF state) In the absence of extracellular amino acids, Stp1 and Stp2 are produced as latent cytoplasmic precursors that are retained in the cytosol due to $\mathrm{N}$-terminal regulatory domains that possess both a cytoplasmic retention motif and a nuclear degron, the latter recognized by the E3-ubiquitin ligase, Asi3. ((Right panel), ON state) In the presence of amino acids, Ssy1 is stabilized in a signaling conformation, which initiates downstream events, resulting in the activation of the Ssy5 protease. Activated Ssy5 endoproteolytically cleaves the N-terminal regulatory domains of Stp1 and Stp2. The shorter, cleaved forms efficiently translocate into the nucleus, where they bind upstream activating sequences (UASaa) and induce the expression of SPS-regulated genes (SRG). Importantly, Stp1 and Stp2 induce divergent subsets of genes, and STP1 expression is under NCR control; STP1 is repressed in cells grown in the presence of millimolar concentrations of amino acids, whereas Stp2 is constitutively expressed. Activated Stp2 induces the expression of amino acid permease (AAP) genes. AAPs are translated and initially inserted in the ER membrane, where they require the assistance of the ERmembrane-localized chaperone Csh3, the ortholog of yeast Shr3, to attain native structures. In the absence of Csh3, AAPs aggregate and are retained in the ER. Activated Stp1 derepresses the expression of $S A P 2$, a secreted protease, and multiple oligopeptide transporter genes that facilitate peptide uptake. Stp1 triggers responses required for host protein utilization, whereas Stp2 induces amino acid utilization.

Additional sensing systems in C. albicans, capable of transmitting signals regarding extracellular amino acid availability, have been reported. The G-protein-coupled receptor (Gpr1) has been proposed to sense extracellular methionine [70] or even glucose, similarly to $S$. cerevisiae [71]. The idea that methionine is the primary activating ligand for Gpr1 stems from the fact that the addition of methionine could trigger the rapid internalization of Gpr1 in a manner consistent with ligand-mediated receptor internalization ([70]; reviewed in [72]). More recently, however, lactate has been proposed to be the primary activating ligand for Gpr1 [73]. Hence, the role of Gpr1 in amino-acid-induced morphogenesis remains to be defined. What is known is that ligand activation of Gpr1 stimulates GTP-GDP exchange in its effector $\mathrm{G} \alpha$ protein Gpa2; the active GTP-bound form of Gpa2 subsequently binds to the $\mathrm{G} \alpha$-binding domain in the $\mathrm{N}$-terminal region of the adenylate cyclase Cyr1, leading to enhanced cAMP production (reviewed in [74,75]). Null mutations of the GPR1 or GPA2 in C. albicans diminish filamentous growth on solid media, and consistently, filamentation can be restored via the addition of exogenous cAMP [71]. Interestingly, although Gpr1 and Gpa2 were initially characterized on the basis of increased cAMP synthesis in response to glucose, deletions of GPR1 or GPA2 do not affect glucose-induced cAMP signaling, and cells remain responsive to methionine and proline $[39,70]$. Furthermore, the levels of cAMP in gpr1-null mutants spike in response to serum or large amounts of glucose $(100 \mathrm{mM}$, or $1.8 \%$ ), suggesting that Cyr1 can be activated by Gpr1-independent processes [70]. 


\section{Amino Acids from Proteins and Peptides}

Although free amino acids are preferred, as they can be rapidly utilized as both carbon and nitrogen sources, the bulk of amino acids in hosts are typically fixed in proteins, e.g., the extracellular matrix proteins collagen and mucin. Consequently, extracellular proteolytic enzymes are required to cleave host proteins to release amino acids and peptide fragments that can subsequently be taken up by the cell. It is important to note that the breakdown of host proteins that occurs at sites of infection can be due to proteases secreted either from the fungal or host cells [76,77]. In vitro, C. albicans can acquire peptides and amino acids derived from extracellular proteins, e.g., albumin, collagen and mucin. This requires the expression of secreted aspartyl proteases (Saps) [78-80] or the activity of matrix metalloproteinases (MMPs) [81,82]. The host can also trigger the proteolytic degradation of tissues as observed in some pathological conditions such as cancer [83] or sarcopenia (muscle wasting) [84]. Once internalized, peptides are then degraded to amino acids through the activity of several intracellular proteases, e.g., metallopeptidase, dipeptidase, carboxypetidases and serine proteases, which liberate free amino acids [85-88]. The induced expression of some of these enzymes is complex and depends on the release from strict regulatory processes, including NCR [68]. Although the overall effect on virulence remains to be clarified, the discovery of the fungal toxin candidalysin is important as it can also trigger the release of free amino acids by contributing to the lysis of host cells [89-91].

\section{Amino Acid Metabolism in C. albicans}

Many amino acids, derived either from extracellular uptake or oligopeptide/protein degradation or released from the vacuolar compartment, are converted to glutamate in the cytosol via the catalytic activity of distinct aminotransferases (ATs) (Figure 5). Specifically, ATs transfer the $\alpha$-amino group of an amino acid to $\alpha$-ketoglutarate ( $\alpha$-KG; 2 -oxoglutarate), resulting in the formation of glutamate. ATs are defined by the amino acid that serves as the amino group donor. ATs collectively contribute to the cytosolic glutamate pool $\left(\mathrm{Glu}_{\mathrm{cyto}}\right)$. Examples include aspartate aminotransferase (Aat1, EC 2.6.1.1), which transfers the $\alpha$-amino group of aspartate to $\alpha-K G$, resulting in glutamate and oxaloacetate; ornithine transaminase (Car2; EC 2.6.1.13), which uses ornithine, forming glutamate and glutamyl5-semialdehyde; alanine transaminase (Alt1; EC 2.6.1.2), which uses alanine, forming glutamate and pyruvate; and glutamate synthase (Glt1; EC 1.4.1.14), which uses glutamine, forming glutamate.

Glutamate is enzymatically converted to $\alpha-\mathrm{KG}$ via oxidative deamination, catalyzed by $\mathrm{NAD}^{+}$-dependent glutamate dehydrogenase (Gdh2; EC 1.4.1.2), yielding ammonia $\left(\mathrm{NH}_{3}\right)$ and reduced NADH $[61,93]$. At a physiologically relevant $\mathrm{pH}$, ammonia is protonated to ammonium $\left(\mathrm{NH}_{4}{ }^{+}\right)$. In mammalian cells, glutamate dehydrogenase is localized in the mitochondria, whereas in S. cerevisiae, there is a lack of consensus regarding its localization; Gdh2 has been reported to be a mitochondrial component [94,95] and alternatively a cytosolic component [96-98]. The bulk of ammonia produced by C. albicans during growth on amino acids as a sole nitrogen and carbon source comes from the reaction catalyzed by Gdh2 [61]. Contrary to the initial publication, now corrected [61], Gdh2 in C. albicans is clearly cytoplasmic. The correct assignment of Gdh2 as a cytoplasmic component is key to understanding its role in cellular energy production, as the reaction reduces $\mathrm{NAD}^{+}$, forming NADH. The ammonium pool in the cytosol generated primarily from Gdh2 activity and possibly from the import of extracellular ammonium via the ammonium transporters Mep1 and Mep2 $[57,99,100]$ can be assimilated by two key anabolic reactions catalyzed by the NADPH-dependent glutamate dehydrogenase (Gdh3, EC 1.4.1.4; Gdh1 in S. cerevisiae) and glutamine synthetase (Gln1; EC 6.3.1.2) (Figure 5). Gdh3 catalyzes the synthesis of glutamate from $\alpha-K G$ and ammonium [93], whereas Gln1 catalyzes the synthesis of glutamine from glutamate and ammonium in an ATP-dependent reaction [93]. In S. cerevisiae, cytosolic glutamate can be imported to the mitochondrial matrix via transporters localized at the inner mitochondrial membrane, such as Agc1 [101-104] or Ymc2 [104]. Putative orthologs of these proteins exist in C. albicans (see CGD, http:/ / www.candidagenome.org (accessed 
on 19 December 2021); C1_13400C for Agc1 and C4_02080W for Ymc2). Furthermore, in S. cerevisiae, cytosolic $\alpha-K G$ can be imported into the mitochondria through oxodicarboxylate carriers that exists in two isoforms, Odc1 and Odc2; Odc1 is used during respiration and its expression is subject to glucose repression, whereas Odc2 is the predominant isoform under non-respiratory conditions $[105,106]$. The C. albicans genome has a putative ortholog for Odc1 (CR_05480W).

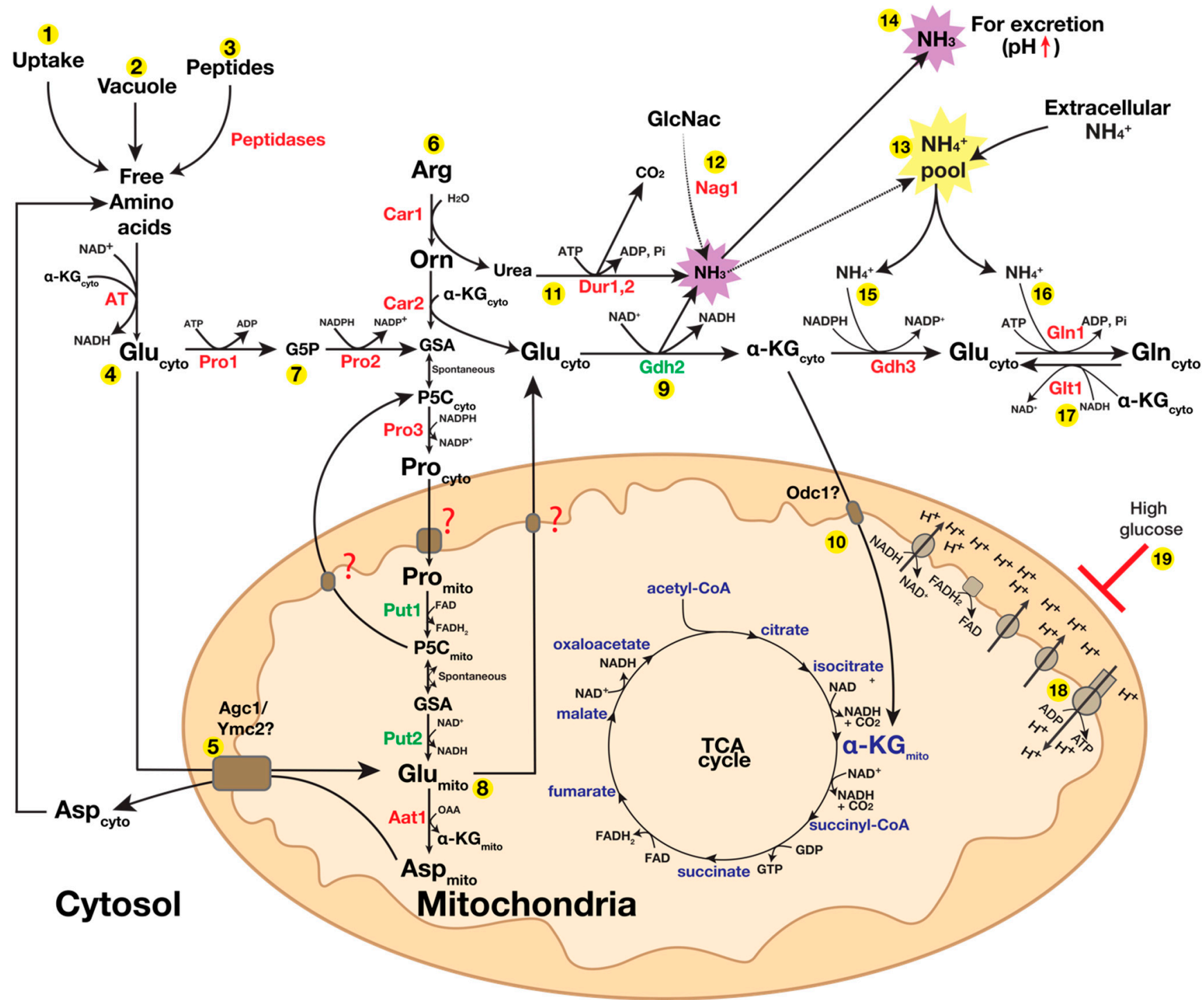

Figure 5. Nitrogen utilization in C. albicans. Most free amino acids, obtained from extracellular uptake (1), vacuolar release (2) or the degradation of small peptides by intracellular peptidases (3), are deaminated by specific aminotransferases (ATs) using $\alpha$-ketoglutarate as the amino group acceptor, forming glutamate. Many ATs are found in the cytosol and there is an abundant supply of glutamate in the cytosol (Glu $\mathrm{u}_{\mathrm{cyto}}$ ) (4). Glutamate can be imported into the mitochondria by transporters, such as Agc1 (5). Arginine and proline are converted to glutamate via the proline catabolic pathway (6). In the cytosolic portion of this pathway, arginine is converted to ornithine and urea by arginase (Car1). Ornithine is rapidly converted to glutamate semialdehyde (GSA) by ornithine transaminase (Car2), which is non-enzymatically converted to the cyclic $\Delta$-1-pyrroline-5-carboxylate (P5C) and then reduced by $\mathrm{P} 5 \mathrm{C}$ reductase (Pro3), generating proline $\left(\mathrm{Pro}_{\mathrm{cyto}}\right)$. Pro $\mathrm{Pito}_{\mathrm{ito}}$ ) via an unidentified transporter. Pro $_{\text {mito }}$ is catabolized to glutamate $\left(\mathrm{Glu}_{\text {mito }}\right)$ via the concerted activities of proline dehydrogenase (Put1) and P5C dehydrogenase (Put2). 
Proline enters the mitochondria (Glutamate produced in the mitochondria $\left(\mathrm{Glu}_{\mathrm{mito}}\right)(8)$ is thought to exit the mitochondria and become part of Glu $u_{\text {cyto. }}$ Glu $u_{\text {cyto }}$ is used in the synthesis of proline (7); glutamate is first activated to produce glutamate-5-phosphate (G5P) by $\gamma$-glutamyl kinase (Pro1), followed by its conversion to GSA/P5C by $\gamma$-glutamyl phosphate reductase (Pro2) and is then reduced to proline by $\mathrm{P} 5 \mathrm{C}$ reductase (Pro3). Cytosolic glutamate can be converted to $\alpha$-ketoglutarate by the $\mathrm{NAD}^{+}$-dependent glutamate dehydrogenase (Gdh2), which is critical for maintaining the $\alpha$-ketoglutarate pool in the cytosol $\left(\alpha-\mathrm{KG}_{\mathrm{cyto}}\right)$. The reaction catalyzed by Gdh2 generates ammonia as a by-product (9). $\alpha$-ketoglutarate can be transported in and out of mitochondria via putative oxodicarboxylate carriers (e.g., Odc1). The mitochondrial $\alpha-\mathrm{KG}_{\text {mito }}$ pool is linked to the TCA cycle (10). Urea, derived either from arginine or from extracellular uptake, can be converted to ammonia and $\mathrm{CO}_{2}$ via urea amidolyase (Dur1,2) (11). When grown in the presence of $\mathrm{N}$-acetylglucosamine (GlcNac), ammonia is also produced when glucosamine-6-phosphate is converted to fructose-6-phosphate through glucosamine-6-phosphate isomerase (Nag1) (12). As the cytosolic $\mathrm{pH}$ is maintained near neutrality ( $\mathrm{pH} \mathrm{6.5),} \mathrm{most} \mathrm{ammonia} \mathrm{is} \mathrm{converted} \mathrm{to} \mathrm{its} \mathrm{protonated} \mathrm{form,} \mathrm{ammonium} \mathrm{(13).} \mathrm{Free} \mathrm{ammonia} \mathrm{is}$ membrane-permeable and can readily exit cells, where it contributes to the alkalization of the growth environment, a consequence of its conversion to ammonium (14). Ammonium in cells can be reassimilated to generate glutamate by the NADPH-dependent glutamate dehydrogenase (Gdh3), which uses $\alpha$-ketoglutarate as a substrate (15); additionally, ammonium can be reassimilated via glutamine synthetase (Gln1), which catalyzes the conversion of glutamate to glutamine (16). Glutamate can also be generated from glutamine and $\alpha$-ketoglutarate via the NADH-dependent glutamate synthase (Glt1) (17). In mitochondria, the $\mathrm{NADH} / \mathrm{FADH}_{2}$ generated by the TCA cycle and proline catabolism can be oxidized via the electron transport chain (ETC) to generate ATP (18). Mitochondrial function and multiple enzymatic activities are repressed in cells grown in the presence of high glucose $(\geq 0.2 \%,(\mathbf{1 9}))$. The localization of enzymes shown in green have been experimentally validated in C. albicans, whereas those shown in red are based on the localization of their corresponding orthologs in S. cerevisiae and the presence or absence of strong mitochondrial pre-sequences in the $\mathrm{N}$-terminals of their respective protein sequences (Candida Genome Database (CGD, http: / / www.candidagenome.org (accessed on 18 December 2021)) analyzed using the MitoFate tool [92]. The following enzymes are present in the $C$. albicans genome-PRODH = PUT1 (C5_02600W), P5CDH = PUT2 (C5_04880C), GDH = GDH2 $\left(\mathrm{C} 2 \_07900 \mathrm{~W}\right), \mathrm{P} 5 \mathrm{CR}=$ PRO3 $\left(\mathrm{C} 4 \_00240\right), \mathrm{OAT}=\mathrm{CAR} 2\left(\mathrm{C} 4 \_00160 \mathrm{C}\right), \mathrm{ARG}=\mathrm{CAR} 1$ (C5_04490C), GK $=$ PRO1 (CR_10580), GPR = PRO2 (C3_07220C). GLN1 (CR_05050W), GLT1 (C1_06550W), DUR1,2 $\left(\mathrm{C} 1 \_04660 \mathrm{~W}\right), \mathrm{NADPH}-d e p e n d e n t \mathrm{GDH}=$ GDH3 (C4_06120W), AAT1 (C2_05250C) and AAT2 = AAT21 (CR_07620W).

In addition to the cytoplasmic glutamate pool ( $\left.\mathrm{Glu}_{\mathrm{cyto}}\right)$, a significant fraction of the intracellular glutamate is generated in the mitochondria $\left(\mathrm{Glu}_{\mathrm{mito}}\right)$ via the proline catabolic pathway. In eukaryotes, the four-electron catabolic conversion of proline to glutamate is carried out through the successive actions of proline dehydrogenase (PRODH; EC 1.5.5.2) and $\Delta 1$-pyrroline-5-carboxylate (P5C) dehydrogenase (P5CDH; EC 1.2.1.88). PRODH and P5CDH are highly conserved enzymes throughout eukaryotes and bacteria (reviewed in [107-110]). In C. albicans, PRODH and P5CDH are called Put1 and Put2, respectively, and both are nuclear-encoded mitochondrial proteins [59,61]; in most eukaryotes, PRODH is associated with the inner mitochondrial membrane and is connected to complex II of the electron transport chain (ETC; reviewed in [110]). Cytosolic proline (Pro cyto $_{\text {, }}$, derived from uptake, biosynthetic reactions or from the catabolism of arginine or ornithine [59], is imported into the mitochondria $\left(\mathrm{Pro}_{\text {mito }}\right)$ via a still-unidentified mitochondrial transporter. $\mathrm{PRODH}$ then transfers two electrons from proline to FAD to generate P5C and the reduced flavin cofactor $\left(\mathrm{FADH}_{2}\right)$. P5C tautomerizes spontaneously in a non-enzymatic reaction, forming glutamic- $\gamma$-semialdehyde (GSA). The prevailing $\mathrm{pH}$ strongly affects the equilibrium between $\mathrm{P} 5 \mathrm{C}$ and GSA; $\mathrm{P} 5 \mathrm{C}$ formation is favored when the $\mathrm{pH}$ is $>6.5$. $\mathrm{P} 5 \mathrm{CDH}$ then catalyzes the oxidation of GSA to glutamate, reducing $\mathrm{NAD}^{+}$to NADH. When high levels of proline are available and catabolized, P5C can accumulate in the mitochondria and exert a toxic effect [111-113]. The reduced cofactors $\mathrm{FADH}_{2}$ and $\mathrm{NADH}$, generated by proline catabolism, are oxidized by the ETC of mitochondria to power ATP generation. Since Gdh2 
catalyzes the conversion of glutamate to $\alpha-\mathrm{KG}$ in the cytosol and that Gdh2-dependent alkalization is tightly linked to mitochondrial function [61], it is highly likely that glutamate resulting from proline catabolism $\left(\mathrm{Glu}_{\text {mito }}\right)$ is able to exit the mitochondria. To date, a dedicated glutamate transporter capable of exporting glutamate out of the mitochondria has yet to be identified. In yeast, mitochondrial glutamate is converted to aspartate by the mitochondrial aspartate aminotransferase (Aat1; EC 2.6.1.1), and aspartate exits the mitochondria via the Agc1 antiporter. The relevance of this transporter with respect to the export of glutamate is not clear, as the antiporter mechanism transports aspartate out and glutamate in. Aspartate in the cytosol can be converted back to glutamate via the cytosolic aspartate aminotransferase (Aat2; EC 2.6.1.1). The C. albicans genome has putative orthologs of Aat1 (AAT1; C2_05250C) and Aat2 (AAT21;CR_07620W). In yeast, cytosolic glutamate is used in the biosynthesis of several amino acids, including proline; $85 \%$ of the total cellular nitrogen is incorporated via the amino nitrogen of glutamate, and the remaining $15 \%$ is derived from the amide nitrogen of glutamine [114].

\section{Mitochondrial Metabolism Is Sensitive to Glucose Availability in C. albicans}

Amino acid metabolism can be directly or indirectly regulated by glucose. Direct control is exerted by Mig1 and Mig2, well-studied factors that bind promoters and repress transcription when glucose is abundant [115]. Indirectly, glucose can negatively and pleiotropically regulate amino acid metabolism by controlling the function of mitochondria. For example, we and others have shown that C. albicans mitochondrial activity can be downregulated by glucose in a manner similar to $S$. cerevisiae, albeit to a lesser extent $[59,116]$. Our data indicate that the repressing effect of glucose is clearly evident in C. albicans at $0.2 \%$ or higher [59], and more sensitive transcriptomic studies have noted effects of $0.01 \%$ glucose, a very low level of glucose [116]. The more pronounced repressive effect of glucose on mitochondrial respiration in $S$. cerevisiae is likely due to the limited capacity to oxidize NADH when glycolytic flux is high [117]. This is expected to be similar in C. albicans; however, since $C$. albicans has a functional complex I with a higher capacity to oxidize $\mathrm{NADH}$, the threshold level for glucose's repression of mitochondrial respiration is higher than that in S. cerevisiae. Consistently, we observed that the level of ATP is higher in $0.2 \%$ glucose than in 2\% glucose [59]. Consistently with the model that ATP-dependent Ras1 activation drives filamentous growth [118], filamentation is more robust when glucose is $<0.2 \%[39,59]$. The lower ATP level observed for cells grown in the presence of $1 \%$ glycerol is likely due to the lower levels of reduced $\mathrm{NADH}$ (low $\mathrm{NADH} / \mathrm{NAD}^{+}$ratio) that can be oxidized to generate the membrane potential needed to generate ATP [59].

The pleiotropic effect of glucose on mitochondrial activity and amino acid catabolism is nicely illustrated by arginine catabolism. Arginine catabolism occurs in a bifurcated manner that generates two products that are independently catabolized either in the cytosol (urea) or mitochondria (proline). When glucose is absent, the proline catabolic pathway becomes essential for arginine catabolism as cells lacking PUT1 or PUT2 failed to grow in the presence of arginine as the sole nitrogen and carbon source, whereas cells lacking DUR1,2 grew [59]. However, when high glucose was added as the main carbon source, the put1-/ - defect was rescued as the metabolism shifted from pure respiratory to mixed types of growth (respiratory/fermentative), shifting the metabolic burden of nitrogen assimilation to the cytosolic Dur1,2. Strikingly, the enzymes required to catabolize proline were still expressed; however, since the mitochondria were repressed by high glucose levels, they were unable to carry out their catabolic functions of converting proline to glutamate.

\section{Ammonia Generation and Excretion}

In the human body, amino acids are an abundant source of nitrogen for C. albicans. However, the utilization of amino acids in excess of the amount necessary to support growth and basic cellular functions must be controlled due to the accumulation of ammonia as a metabolic byproduct. Excess ammonia is toxic to cells. When cells are grown using amino acids as energy sources, excess ammonia exits into the extracellular medium, resulting 
in environmental alkalization (Figure 6A). Interestingly, this capacity to increase environmental $\mathrm{pH}$ via ammonia extrusion is believed to support the pathogenic growth of fungal pathogens such as C. albicans in certain acidic microenvironments, e.g., the phagosome of macrophages (reviewed in $[119,120]$ ).

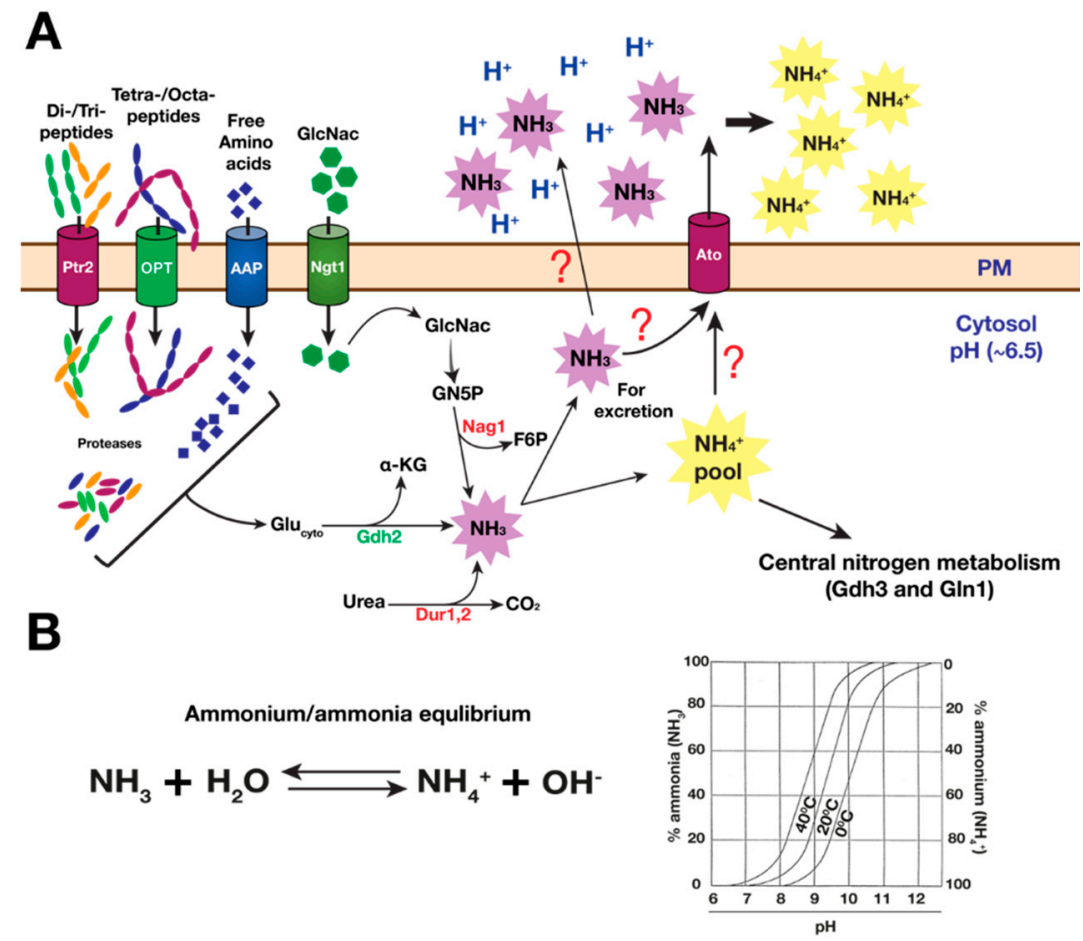

Figure 6. Ammonia extrusion in C. albicans. (A) When C. albicans utilizes amino acids or Nacetylglucosamine ( $\mathrm{GlcNac}$ ) as nitrogen sources for growth, ammonia is produced, promoting the alkalization of the extracellular $\mathrm{pH}$. Amino acids can be either free or derived internally from the proteolytic degradation of oligopeptides, which are then converted to glutamate either in the cytosol (by specific aminotransferases) or mitochondria (proline catabolism), creating a glutamate pool in the cytosol $\left(\mathrm{Glu}_{\text {cyto }}\right)$. The $\mathrm{NAD}^{+}$-dependent glutamate dehydrogenase (Gdh2) catalyzes the conversion of $\mathrm{Glu}_{\mathrm{cyto}}$ to $\alpha$-ketoglutarate, releasing ammonia in the process. Urea generated via arginine catabolism (or from the extracellular environment) can also be degraded to ammonia via the urea amidolyase (Dur1,2) enzyme. The deamination of GlcNac is dependent on glucosamine-6-phosphate isomerase (Nag1), which catalyzes the conversion of glucosamine-5-phosphate (GN5P) to fructose 6-phosphate (F6P). Excess ammonia produced in the cytosol must be removed in order to avoid its toxic effects; due to the cytosolic $\mathrm{pH}$ of around 6.5, most of the free ammonia $\left(\mathrm{NH}_{3}\right)$ is converted to ammonium $\left(\mathrm{NH}_{4}{ }^{+}\right)$(see graph below), which can be directly assimilated via central nitrogen metabolism (i.e., Gdh3 and Gln1), whereas a small fraction is released into the environment, where it could neutralize the acidic $\mathrm{pH}$, producing ammonium $\left(\mathrm{NH}_{4}{ }^{+}\right)$. Whether ammonia (or even ammonium) is exported through simple diffusion or via exporters (Ato) requires further study. (B) At the normal cytosolic $\mathrm{pH}$ of $\approx 6.5$, ammonia $\left(\mathrm{NH}_{3}\right)$ is converted to ammonium $\left(\mathrm{NH}_{4}{ }^{+}\right)$. We present a plot showing the relative concentrations of $\mathrm{NH}_{3}$ and $\mathrm{NH}_{4}{ }^{+}$in aqueous solution based on $\mathrm{pH}$ and temperature. Image adapted and redrawn from Huang, J; Handbook of Environmental Engineering) [121]. The ratio of $\mathrm{NH}_{4}{ }^{+}$ to $\mathrm{NH}_{3}$ in this equilibrium is highly $\mathrm{pH}$-dependent. At low acidic $\mathrm{pH}$, the ammonium form $\left(\mathrm{NH}_{4}{ }^{+}\right)$ dominates. As the $\mathrm{pH}$ increases, the ammonia $\left(\mathrm{NH}_{3}\right)$ form also increases, and the proportion becomes equal at the $\mathrm{pKa}$ value. Higher temperatures favor the $\mathrm{NH}_{3}$ gas side of the equilibrium balance with $\mathrm{NH}_{4}{ }^{+}$.

It has been proposed that ammonia derived from amino acid catabolism enables C. albicans cells to neutralize the acidic luminal $\mathrm{pH}$ of the phagosome, reducing the activities of hydrolytic enzymes with low $\mathrm{pH}$ optima and inducing $C$. albicans to switch 
morphologies, resulting in hyphal growth, thus facilitating macrophage evasion [31]. This model was largely premised on studies using a strain lacking STP2 $(\operatorname{stp} 2 \Delta / \Delta)$, the SPS transcription factor that positively regulates the expression of amino acid permeases required for amino acid uptake [31,32]. Strains carrying stp $2 \Delta / \Delta$ exhibit defects in both environmental alkalization and the capacity to escape the phagosome of the engulfing macrophage [31,32]. This model assigned the critical ammonia-generating event to the urea amidolyase (Dur1,2), which catalyzes the conversion of urea to ammonia and $\mathrm{CO}_{2}$, as cells lacking this enzyme $(d u r 1,2 \Delta / \Delta)$ show alkalization defects when cells are grown in media with high glucose [32]. However, Dur1,2 has only been linked to ammonia generation in the presence of its substrate urea, and DUR1,2 expression is under tight NCR control [44,56]. Thus, it is unlikely that Dur1,2 contributes to the alkalization of a growth medium with abundant preferred nitrogen sources such as amino acids and even ammonium sulfate.

There is mounting evidence that alkalization of the phagosomal compartment is not requisite for $C$. albicans cells to evade macrophages. Results obtained using dual-wavelength ratiometric fluorescence imaging to quantify the $\mathrm{pH}$ in the phagosome revealed that increased phagosomal $\mathrm{pH}$ is the consequence of elongating hyphal cells, physically stretching the phagosomal membrane, causing transient leaks [122]. The induction of hyphal growth was observed to precede alkalization. In addition, the proton-pumping activity of V-ATPase exceeds the rate of ammonia extrusion by several orders of magnitude [122]. Recently, we reported that Gdh2, the enzyme that catalyzes the conversion of glutamate to $\alpha-K G$, is responsible for the bulk of ammonia produced from amino acid metabolism [61]; a gdh2null strain is unable to alkalize a medium containing amino acids as the sole nitrogen and carbon source. Surprisingly, the capacity of $g d h 2-/-$ mutants to escape the macrophage phagosome or its virulence in murine systemic infection model was not affected, indicating that amino acid-dependent environmental alkalization is not essential for the virulence of C. albicans. Consistently with a previous report [122], we observed that viable wildtype cells pre-stained with a $\mathrm{pH}$-sensitive dye (pHrodo), of which the fluorescence intensity varied inversely to $\mathrm{pH}$, were retained in acidic phagosomes, and this observation is was even when a high MOI (more ammonia-extruding cells) was used [61].

In C. albicans, Gdh2 is a cytosolic component [61] and its expression is independent of NCR; Gdh2 is well expressed in cells grown in a medium with high levels of amino acids, even when supplemented with high levels of ammonium sulfate [61]. Consistently, a strain lacking GLN3 and GAT1, which encode for the GATA transcription factors activating NCRsensitive genes, remain alkalization-competent (our unpublished data). Despite its cytosolic localization, Gdh2-dependent alkalization is tightly linked to mitochondrial function as acute inhibition of the mitochondria with a sublethal dose of antimycin, a potent respiratory complex III inhibitor, virtually abolished alkalization in wildtype cells even when a very high starting cell density was used $\left(\mathrm{OD}_{600} \approx 5\right)[61]$. Since proline catabolism is a major source of glutamate in the mitochondria and since this alkalization is partially dependent on proline catabolism [61], it is likely that pharmacological inhibition of the mitochondria pleiotropically prevented either the generation or export of mitochondrial glutamate. In a similar way, the inability of $C$. albicans to alkalinize the extracellular environment when grown in the presence of high glucose $(2 \%)$ is likely due to the capacity of glucose to pleiotropically inhibit or downregulate mitochondrial function $[59,116]$. Gdh2 levels appear to be regulated by $\mathrm{pH}$ as the protein levels decrease as the $\mathrm{pH}$ of the growth medium approaches neutrality, which is consistent with the observed dependency of alkalization on the starting cell density [61]. In addition to amino acids, growth on $\mathrm{N}$-acetylglucosamine (GlcNac) can also raise extracellular $\mathrm{pH}$ via ammonia extrusion. However, the origin of alkalinizing ammonia is distinct as it is catalyzed by the enzyme glucosamine-6-phosphate isomerase (Nag1), which deaminates glucosamine-5-phosphate (GN5P), converting it to fructose 6-phosphate (F6P) [123].

Regarding the fate of intracellular ammonia, in aqueous solution, ammonia can exist either as a gas $\left(\mathrm{NH}_{3}\right.$, ammonia) or as a cationic $\left(\mathrm{NH}_{4}{ }^{+}\right.$, ammonium) species; the ratio (ammonia/ammonium) increases with $\mathrm{pH}(\mathrm{pKa}=9.25)$ (Figure 6B). Since the $\mathrm{pH}$ of the cytosol 
in actively growing C. albicans wildtype cells is maintained at $~ 6.5$ [124], the protonated form $\mathrm{NH}_{4}{ }^{+}$predominates and can be directly assimilated by the NADPH-dependent glutamate dehydrogenase (Gdh3) or glutamine synthetase (Gln1). Due to its being positively charged, ammonium cannot readily diffuse out of cells, but rather requires transporters or channels to traverse the phospholipid bilayer of biomembranes. A small fraction of the total ammonia species exists in the unprotonated form $\left(\mathrm{NH}_{3}\right)$ that can be released into the extracellular space, where it could exert its neutralizing effect by reacting to the hydrogen ions $\left(\mathrm{H}^{+}\right)$, generating ammonium $\left(\mathrm{NH}_{4}{ }^{+}\right)$. How ammonia traverses the plasma membrane from the cytosol is unclear, as proposed earlier, because ammonia extrusion requires the ammonia transport outward (Ato) proteins, a family of plasma-membrane-bound proteins thought to facilitate ammonia export [32,125]. Strains lacking ATO5 (ato5 $\Delta / \Delta)$ or a dominant point mutation in ATO1 (ATO1 ${ }^{\mathrm{G} 53 \mathrm{D}}$ ) show strong alkalization defects, and consistently, the overexpression of ATO genes accelerates alkalization [32,125]. However, it is also known that ammonia $\left(\mathrm{NH}_{3}\right)$ is membrane-permeable and can easily diffuse out of yeast cells [126-128]. Whether ammonia (or even ammonium) is exported through simple diffusion or via exporters (Ato) remains to be clarified.

In addition to ammonia extrusion, yeast cells have an alternative mechanism to minimize the toxic effects of ammonia. S. cerevisiae can indirectly limit the production of ammonia by excreting cytosolic amino acids such as glutamate to the extracellular space via proteins that belong to the multidrug resistance transporter family that are thought to function as $\mathrm{H}^{+}$antiporters (e.g., Aqr1) [129]. Whether the same amino acid extrusion process, limiting intracellular ammonia production, operate in C. albicans is not yet known but a putative $A Q R 1$ homolog has been identified in the $C$. albicans genome (QDR2/C3_05570W). Qdr2 may perform the same function, constituting a rudimentary ammonia detoxification mechanism in C. albicans.

\section{Conclusions and Outlook}

C. albicans is an opportunistic fungal pathogen that is intimately linked to its human hosts. Since C. albicans grows in symbiosis with humans, fungal cells must survive and propagate under identical physiological conditions as human cells. The capacity of C. albicans to establish persistent infections relies heavily on their capacity to assimilate nutrients in a competitive landscape where both hosts cells and even other members of the microbiome compete for nutrients. Amino acids are among the most versatile nutrients available in the hosts; they can be assimilated as both nitrogen and carbon precursors, transformed to key metabolic intermediates or utilized to modulate extracellular $\mathrm{pH}$ via ammonia formation. Although S. cerevisiae paved the way for most of our understanding of nutrient assimilation and metabolic processes in yeasts, there are clearly significant differences that exist in C. albicans that must be taken into account as they are crucial to our understanding of how this fungal pathogen assimilate nutrients in the host, especially in the context of infectious growth.

Some of the so-called poor or non-preferred nitrogen sources in S. cerevisiae, such as proline, are efficiently utilized by C. albicans. This observation is in alignment with recent findings that the enzymes required to utilize proline in C. albicans are independent of NCR, allowing the unrestricted utilization of proline regardless of whether other nitrogen sources are available $[59,60]$. Proline constitutes some of the most abundant proteins in humans (e.g., collagen, mucin); thus, given that $C$. albicans possesses a multi-subunit respiratory complex I (NADH dehydrogenase), similar to human cells, it is not surprising if C. albicans evolved to prefer this amino acid as an energy source for growth. Interestingly, proline has long been known as one of the most potent inducers of yeast-to-hyphal transitions, a key virulence factor in C. albicans [59,130-133]. We have shown that the induction of morphogenesis occurs via ATP-dependent Ras1 activation [59]. One molecule of proline can be completely oxidized to generate approximately 30 ATP equivalents [134,135], reinforcing the idea that proline is an important energy source for many types of cells, especially under nutrient-limited conditions. We have shown that $C$. albicans growth in 
the phagosome of the macrophage is dependent on proline catabolism to obtain energy to survive despite a multitude of environmental stresses [59]. The inadvertent replication of our previous data [59] in the corrected paper [61] highlights the idea that proline is sensed by $C$. albicans in the phagosome of macrophages. Our data are also consistent with recent transcriptomic data showing that proline induced the expression of ICL1, a gene encoding the key glyoxylate cycle enzyme isocitrate lyase 1 (Icl1), which is known to be derepressed in C. albicans, being engulfed by macrophages [60]. Consequently, strains lacking the capacity to utilize proline have defects in escaping the phagosome of macrophages [59]. In terms of environmental alkalization, proline catabolism plays a major role by virtue of glutamate production (Put2 product). In the presence of arginine as the sole nitrogen and carbon source, proline catabolism is essential as it is the primary catabolic route to generate glutamate, which can then be subsequently catabolized by Gdh2 to ammonia and $\alpha-K G$, a key TCA cycle intermediate. However, in the presence of other amino acids, the proline catabolic pathway becomes less essential for alkalization as other amino acids can be transaminated to generate glutamate (Figure 5). Proline utilization in C. albicans provides a clear example of how evolution influences and fine-tunes metabolism, leading to unique capabilities, in this case to the utilization of nutrients in a manner not relevant for other related yeasts. Consequently, a thorough examination of other amino acid catabolic pathways in C. albicans is warranted, the premise being that many important regulatory differences may exist, and that these may be specifically linked to the evolution of C. albicans within mammalian hosts.

A major challenge to correctly interpret experimental results derived from studies examining nutrient sensing and assimilation in C. albicans is understanding how laboratory growth conditions influence the results. Many of the standard laboratory conditions do not reflect the mammalian micro-niches in which $C$. albicans resides. For example, many host-pathogen interaction experiments involving innate immune cells are carried out in cell culture medium (RPMI or DMEM) containing 5-10\% fetal bovine serum. These media readily trigger filamentous growth in C. albicans, independently of host cell interactions (e.g., with macrophages), resulting in the false impression that certain genes are not important for the survival of $C$. albicans during co-culture with innate immune cells. This is especially crucial when looking at the role of specific genes that are required for nitrogen acquisition. For example, there is a possibility that the importance of certain genes under NCR control will be erroneously dismissed as they are not expressed under nitrogen-replete conditions such as those in cell culture media. In addition, it is common practice to use strains pregrown in YPD, a complex medium that is high in glucose $(2 \%)$ and rich in nitrogen (amino acids, peptides), prior to shifting cells to desired experimental test conditions. In humans, the level of blood glucose is maintained within homeostatic limits $(0.05-0.1 \% ; 3-5 \mathrm{mM}$ glucose) that are well below the level used in YPD [116]. The dramatic reorientation of metabolism resulting from merely shifting conditions is likely to influence the response, and in many instances may provide a conflicting readout. For example, yeast cells grown in YPD build up an extensive reservoir of amino acids with vacuolar pools during growth in nitrogen-rich conditions [136,137]. This influences nutrient-based signals. Furthermore, many studies have relied on fixed-point microscopy coupled with differential staining to observe and deduce the role of specific mutations on filamentous growth. This approach relies heavily on observing obvious growth defects that may not be readily apparent on strains lacking genes relevant to nutrient acquisition. Although useful information has been obtained, many of these results often reflect "general" rather than "niche-specific" hyphal defects, highlighting the need to identify more suitable laboratory conditions that better mimic mammalian microenvironments.

Although a great deal of information regarding nutrient-induced processes in C. albicans is accumulating, there are major gaps in our knowledge with respect to the contribution of the host. The availability of assimilable nitrogen sources, i.e., the abundance of amino acids released as a result of host activities, is often overlooked. The contribution of host-derived activities to the degradation of the extracellular matrix (ECM) during stress due to the 
proteolytic activities of proteases secreted by different cell types is not fully understood. For example, in people of advanced age, who due to medical advances represent a growing population, often suffer from sarcopenia or muscle wasting. A hallmark of sarcopenia is that the amino acid proline is elevated in the blood, indicating the degradation of structural proteins rich in proline such as collagen [84]. Indeed, the elevation of free amino acids in the blood is linked to other pathological states in humans, including cancer [83,84]. It is likely that amino acid limitation influences the capacity of cancer cells to establish malignant forms of growth; cancer cells have been found to exhibit enhanced rates of amino acid uptake [138]. Furthermore, amino acid metabolism is an important factor during wasting in cancer patients (cachexia) and in aging individuals [139,140]. Clearly, illuminating the entire repertoire of regulatory mechanisms associated with amino acid signaling is crucial to understanding life processes in both healthy and disease states, and studies in C. albicans may provide important insights with clear therapeutic applications.

Author Contributions: Conceptualization, F.G.S.S. and P.O.L.; writing—original draft preparation, F.G.S.S.; writing-review and editing, F.G.S.S. and P.O.L.; visualization, F.G.S.S.; funding acquisition, P.O.L. All authors have read and agreed to the published version of the manuscript.

Funding: Original research in our laboratory is supported by the Swedish Research Council (P.O.L.) VR-M 2019-01547.

\begin{abstract}
Acknowledgments: We would like to thank the members of the Ljungdahl laboratory for their patience and constructive comments throughout the course of this work. Many colleagues have contributed with strains and important insights and are collectively acknowledged. Furthermore, the vastness of the subject matter and space limitations have precluded the referencing of all relevant papers, and undoubtedly we have failed to cite some papers of equal or greater value than the ones cited; we apologize for the inadvertent omission of uncited work.
\end{abstract}

Conflicts of Interest: The authors declare no conflict of interest.

\title{
References
}

1. Poloni, J.A.T.; Rotta, L.N. Urine Sediment Findings and the Immune Response to Pathologies in Fungal Urinary Tract Infections Caused by Candida spp. J. Fungi 2020, 6, 245. [CrossRef]

2. Behzadi, P.; Behzadi, E.; Yazdanbod, H.; Aghapour, R.; Akbari Cheshmeh, M.; Salehian Omran, D. Urinary Tract Infections Associated with Candida albicans. Maedica 2010, 5, 277-279.

3. Rivett, A.G.; Perry, J.A.; Cohen, J. Urinary candidiasis: A prospective study in hospital patients. Urol. Res. 1986, 14, 183-186. [CrossRef]

4. Harris, A.D.; Castro, J.; Sheppard, D.C.; Carmeli, Y.; Samore, M.H. Risk factors for nosocomial candiduria due to Candida glabrata and Candida albicans. Clin. Infect. Dis. 1999, 29, 926-928. [CrossRef]

5. Lundstrom, T.; Sobel, J. Nosocomial candiduria: A review. Clin. Infect. Dis. 2001, 32, 1602-1607.

6. Kim, J.; Kim, D.S.; Lee, Y.S.; Choi, N.G. Fungal urinary tract infection in burn patients with long-term foley catheterization. Korean J. Urol. 2011, 52, 626-631. [CrossRef]

7. Jakubowska, A.; Kilis-Pstrusinska, K.; Pukajlo-Marczyk, A.; Samir, S.; Baglaj, M.; Zwolinska, D. Fungal urinary tract infection complicated by acute kidney injury in an infant with intestino-vesical fistula. Postepy Hig. Med. Dosw. 2013, 67, 719-721. [CrossRef]

8. Mazo, E.B.; Popov, S.V.; Shmel'kov, I. Fungal infections of the urinary tract. Urologiia 2007, 5, 67-70.

9. Fisher, J.F. Candida urinary tract infections-Epidemiology, pathogenesis, diagnosis, and treatment: Executive summary. Clin. Infect. Dis. 2011, 52 (Suppl. 6), S429-S432. [CrossRef]

10. Kauffman, C.A.; Fisher, J.F.; Sobel, J.D.; Newman, C.A. Candida urinary tract infections-Diagnosis. Clin. Infect. Dis. 2011, 52 (Suppl. 6), S452-S456. [CrossRef]

11. Veroux, M.; Corona, D.; Giuffrida, G.; Gagliano, M.; Tallarita, T.; Giaquinta, A.; Zerbo, D.; Cappellani, A.; Veroux, P.F. Acute renal failure due to ureteral obstruction in a kidney transplant recipient with Candida albicans contamination of preservation fluid. Transpl. Infect. Dis. 2009, 11, 266-268. [CrossRef]

12. Nishimoto, G.; Tsunoda, Y.; Nagata, M.; Yamaguchi, Y.; Yoshioka, T.; Ito, K. Acute renal failure associated with Candida albicans infection. Pediatr. Nephrol. 1995, 9, 480-482. [CrossRef]

13. Shimada, S.; Nakagawa, H.; Shintaku, I.; Saito, S.; Arai, Y. Acute renal failure as a result of bilateral ureteral obstruction by Candida albicans fungus balls. Int. J. Urol. 2006, 13, 1121-1122. [CrossRef] [PubMed]

14. Ekpanyapong, S.; Reddy, K.R. Fungal and Parasitic Infections of the Liver. Gastroenterol. Clin. N. Am. 2020, 49, 379-410. [CrossRef] [PubMed] 
15. Fiore, M.; Cascella, M.; Bimonte, S.; Maraolo, A.E.; Gentile, I.; Schiavone, V.; Pace, M.C. Liver fungal infections: An overview of the etiology and epidemiology in patients affected or not affected by oncohematologic malignancies. Infect. Drug Resist. 2018, 11, 177-186. [CrossRef]

16. Gupta, A.; Bhowmik, D.M.; Dogra, P.M.; Mendonca, S.; Gupta, A. Candida lung abscesses in a renal transplant recipient. Saudi J. Kidney Dis. Transpl. 2013, 24, 315-317. [CrossRef]

17. Shweihat, Y.; Perry, J., 3rd; Shah, D. Isolated Candida infection of the lung. Respir. Med. Case Rep. 2015, 16, 18-19. [CrossRef]

18. Yokoyama, T.; Sasaki, J.; Matsumoto, K.; Koga, C.; Ito, Y.; Kaku, Y.; Tajiri, M.; Natori, H.; Hirokawa, M. A necrotic lung ball caused by co-infection with Candida and Streptococcus pneumoniae. Infect. Drug Resist. 2011, 4, 221-224. [CrossRef]

19. Schmidt, H.; Fischedick, A.R.; Peters, P.E.; von Lengerke, H.J. Candida abscesses in the liver and spleen. The sonographic and computed tomographic morphology. Dtsch. Med. Wochenschr. 1986, 111, 816-820. [CrossRef] [PubMed]

20. Raina, V.; Young, P.T.; Foulis, A.K.; Soukop, M. Hypersplenism due to fungal infection of spleen in a successfully treated patient with Hodgkin's disease. Postgrad. Med. J. 1989, 65, 83-85. [CrossRef] [PubMed]

21. Bezerra, L.S.; Silva, J.A.D.; Santos-Veloso, M.A.O.; Lima, S.G.; Chaves-Markman, A.V.; Juca, M.B. Antifungal Efficacy of Amphotericin B in Candida albicans Endocarditis Therapy: Systematic Review. Braz. J. Cardiovasc. Surg. 2020, 35, 789-796. [CrossRef]

22. Filizcan, U.; Cetemen, S.; Enc, Y.; Cakmak, M.; Goksel, O.; Eren, E. Candida albicans endocarditis and a review of fungal endocarditis: Case report. Heart Surg. Forum 2004, 7, E312-E314. [CrossRef]

23. Mugge, A.; Daniel, W.G.; Nonnast-Daniel, B.; Schroder, E.; Trotschel, H.; Lichtlen, P.R. Renal infarction with fatal bleeding-an unusual complication of Candida albicans endocarditis. Klin. Wochenschr. 1987, 65, 1169-1172. [CrossRef]

24. Oner, T.; Korun, O.; Celebi, A. Rare presentation of Candida albicans: Infective endocarditis and a pulmonary coin lesion. Cardiol. Young 2018, 28, 602-604. [CrossRef]

25. Prabhu, R.M.; Orenstein, R. Failure of caspofungin to treat brain abscesses secondary to Candida albicans prosthetic valve endocarditis. Clin. Infect. Dis. 2004, 39, 1253-1254. [CrossRef] [PubMed]

26. Sheikh, T.; Tomcho, J.C.; Awad, M.T.; Zaidi, S.R. Candida albicans endocarditis involving a normal native aortic valve in an immunocompetent patient. BMJ Case Rep. 2020, 13, e236902. [CrossRef]

27. Ancalle, I.M.; Rivera, J.A.; Garcia, I.; Garcia, L.; Valcarcel, M. Candida albicans meningitis and brain abscesses in a neonate: A case report. Bol. Asoc. Med. Puerto Rico 2010, 102, 45-48. [PubMed]

28. Black, J.T. Cerebral candidiasis: Case report of brain abscess secondary to Candida albicans, and review of literature. J. Neurol. Neurosurg. Psychiatry 1970, 33, 864-870. [CrossRef] [PubMed]

29. Tweddle, D.A.; Graham, J.C.; Shankland, G.S.; Kernahan, J. Cerebral candidiasis in a child 1 year after leukaemia. Br. J. Haematol. 1998, 103, 795-797. [CrossRef] [PubMed]

30. Zhang, S.C. Cerebral candidiasis in a 4-year-old boy after intestinal surgery. J. Child Neurol. 2015, 30, 391-393. [CrossRef]

31. Vylkova, S.; Lorenz, M.C. Modulation of phagosomal $\mathrm{pH}$ by Candida albicans promotes hyphal morphogenesis and requires Stp2p, a regulator of amino acid transport. PLoS Pathog. 2014, 10, e1003995. [CrossRef]

32. Vylkova, S.; Carman, A.J.; Danhof, H.A.; Collette, J.R.; Zhou, H.; Lorenz, M.C. The fungal pathogen Candida albicans autoinduces hyphal morphogenesis by raising extracellular pH. mBio 2011, 2, e00055-11. [CrossRef] [PubMed]

33. Bakker, B.M.; Overkamp, K.M.; van Maris, A.J.; Kotter, P.; Luttik, M.A.; van Dijken, J.P.; Pronk, J.T. Stoichiometry and compartmentation of NADH metabolism in Saccharomyces cerevisiae. FEMS Microbiol. Rev. 2001, 25, 15-37. [CrossRef] [PubMed]

34. Noble, S.M.; Gianetti, B.A.; Witchley, J.N. Candida albicans cell-type switching and functional plasticity in the mammalian host. Nat. Rev. Microbiol. 2017, 15, 96-108. [CrossRef] [PubMed]

35. Garbe, E.; Vylkova, S. Role of Amino Acid Metabolism in the Virulence of Human Pathogenic Fungi. Curr. Clin. Microbiol. Rep. 2019, 6, 108-119. [CrossRef]

36. Martinez, P.; Ljungdahl, P.O. Divergence of Stp1 and Stp2 transcription factors in Candida albicans places virulence factors required for proper nutrient acquisition under amino acid control. Mol. Cell. Biol. 2005, 25, 9435-9446. [CrossRef]

37. Martinez, P.; Ljungdahl, P.O. An ER packaging chaperone determines the amino acid uptake capacity and virulence of Candida albicans. Mol. Microbiol. 2004, 51, 371-384. [CrossRef] [PubMed]

38. Brega, E.; Zufferey, R.; Mamoun, C.B. Candida albicans Csy1p is a nutrient sensor important for activation of amino acid uptake and hyphal morphogenesis. Eukaryot. Cell 2004, 3, 135-143. [CrossRef]

39. Maidan, M.M.; Thevelein, J.M.; Van Dijck, P. Carbon source induced yeast-to-hypha transition in Candida albicans is dependent on the presence of amino acids and on the G-protein-coupled receptor Gpr1. Biochem. Soc. Trans. 2005, 33, 291-293. [CrossRef]

40. Kraidlova, L.; Schrevens, S.; Tournu, H.; Van Zeebroeck, G.; Sychrova, H.; Van Dijck, P. Characterization of the Candida albicans Amino Acid Permease Family: Gap2 Is the Only General Amino Acid Permease and Gap4 Is an S-Adenosylmethionine (SAM) Transporter Required for SAM-Induced Morphogenesis. mSphere 2016, 1, e00284-16. [CrossRef]

41. Dunkel, N.; Biswas, K.; Hiller, E.; Fellenberg, K.; Satheesh, S.V.; Rupp, S.; Morschhauser, J. Control of morphogenesis, protease secretion and gene expression in Candida albicans by the preferred nitrogen source ammonium. Microbiology 2014, 160, 1599-1608. [CrossRef]

42. Du, H.; Ennis, C.L.; Hernday, A.D.; Nobile, C.J.; Huang, G. N-Acetylglucosamine (GlcNAc) Sensing, Utilization, and Functions in Candida albicans. J. Fungi 2020, 6, 129. [CrossRef] 
43. Alvarez, F.J.; Konopka, J.B. Identification of an N-acetylglucosamine transporter that mediates hyphal induction in Candida albicans. Mol. Biol. Cell 2007, 18,965-975. [CrossRef]

44. Navarathna, D.H.; Das, A.; Morschhauser, J.; Nickerson, K.W.; Roberts, D.D. Dur3 is the major urea transporter in Candida albicans and is co-regulated with the urea amidolyase Dur1,2. Microbiology 2011, 157, 270-279. [CrossRef]

45. Dunkel, N.; Hertlein, T.; Franz, R.; Reuss, O.; Sasse, C.; Schafer, T.; Ohlsen, K.; Morschhauser, J. Roles of different peptide transporters in nutrient acquisition in Candida albicans. Eukaryot. Cell 2013, 12, 520-528. [CrossRef] [PubMed]

46. Reuss, O.; Morschhauser, J. A family of oligopeptide transporters is required for growth of Candida albicans on proteins. Mol. Microbiol. 2006, 60, 795-812. [CrossRef] [PubMed]

47. Ljungdahl, P.O.; Daignan-Fornier, B. Regulation of amino acid, nucleotide, and phosphate metabolism in Saccharomyces cerevisiae. Genetics 2012, 190, 885-929. [CrossRef] [PubMed]

48. Georis, I.; Feller, A.; Vierendeels, F.; Dubois, E. The yeast GATA factor Gat1 occupies a central position in nitrogen catabolite repression-sensitive gene activation. Mol. Cell. Biol. 2009, 29, 3803-3815. [CrossRef] [PubMed]

49. Georis, I.; Tate, J.J.; Feller, A.; Cooper, T.G.; Dubois, E. Intranuclear function for protein phosphatase $2 A$ : Pph21 and Pph22 are required for rapamycin-induced GATA factor binding to the DAL5 promoter in yeast. Mol. Cell. Biol. 2011, 31, 92-104. [CrossRef]

50. Cunningham, T.S.; Cooper, T.G. Expression of the DAL80 gene, whose product is homologous to the GATA factors and is a negative regulator of multiple nitrogen catabolic genes in Saccharomyces cerevisiae, is sensitive to nitrogen catabolite repression. Mol. Cell. Biol. 1991, 11, 6205-6215. [PubMed]

51. Coffman, J.A.; Rai, R.; Cunningham, T.; Svetlov, V.; Cooper, T.G. Gat1p, a GATA family protein whose production is sensitive to nitrogen catabolite repression, participates in transcriptional activation of nitrogen-catabolic genes in Saccharomyces cerevisiae. Mol. Cell. Biol. 1996, 16, 847-858. [CrossRef] [PubMed]

52. Soussi-Boudekou, S.; Vissers, S.; Urrestarazu, A.; Jauniaux, J.C.; André, B. Gzf3p, a fourth GATA factor involved in nitrogenregulated transcription in Saccharomyces cerevisiae. Mol. Microbiol. 1997, 23, 1157-1168. [CrossRef] [PubMed]

53. Rowen, D.W.; Esiobu, N.; Magasanik, B. Role of GATA factor Nil2p in nitrogen regulation of gene expression in Saccharomyces cerevisiae. J. Bacteriol. 1997, 179, 3761-3766. [CrossRef] [PubMed]

54. Coffman, J.A.; Rai, R.; Loprete, D.M.; Cunningham, T.; Svetlov, V.; Cooper, T.G. Cross regulation of four GATA factors that control nitrogen catabolic gene expression in Saccharomyces cerevisiae. J. Bacteriol. 1997, 179, 3416-3429. [CrossRef]

55. Limjindaporn, T.; Khalaf, R.A.; Fonzi, W.A. Nitrogen metabolism and virulence of Candida albicans require the GATA-type transcriptional activator encoded by GAT1. Mol. Microbiol. 2003, 50, 993-1004. [CrossRef]

56. Liao, W.L.; Ramon, A.M.; Fonzi, W.A. GLN3 encodes a global regulator of nitrogen metabolism and virulence of C. albicans. Fungal Genet. Biol. 2008, 45, 514-526. [CrossRef]

57. Dabas, N.; Morschhauser, J. Control of ammonium permease expression and filamentous growth by the GATA transcription factors GLN3 and GAT1 in Candida albicans. Eukaryot. Cell 2007, 6, 875-888. [CrossRef]

58. Magasanik, B.; Kaiser, C.A. Nitrogen regulation in Saccharomyces cerevisiae. Gene 2002, 290, 1-18. [CrossRef]

59. Silao, F.G.S.; Ward, M.; Ryman, K.; Wallstrom, A.; Brindefalk, B.; Udekwu, K.; Ljungdahl, P.O. Mitochondrial proline catabolism activates Ras1/cAMP/PKA-induced filamentation in Candida albicans. PLoS Genet. 2019, 15, e1007976. [CrossRef]

60. Tebung, W.A.; Omran, R.P.; Fulton, D.L.; Morschhauser, J.; Whiteway, M. Put3 Positively Regulates Proline Utilization in Candida albicans. mSphere 2017, 2, e00354-17. [CrossRef]

61. Silao, F.G.S.; Ryman, K.; Jiang, T.; Ward, M.; Hansmann, N.; Molenaar, C.; Liu, N.N.; Chen, C.; Ljungdahl, P.O. Glutamate dehydrogenase (Gdh2)-dependent alkalization is dispensable for escape from macrophages and virulence of Candida albicans. PLoS Pathog. 2020, 16, e1008328, Correction in PLoS Pathog. 2021, 17, e1009877. [CrossRef]

62. Miramon, P.; Lorenz, M.C. The SPS amino acid sensor mediates nutrient acquisition and immune evasion in Candida albicans. Cell. Microbiol. 2016, 18, 1611-1624. [CrossRef] [PubMed]

63. Boban, M.; Zargari, A.; Andreasson, C.; Heessen, S.; Thyberg, J.; Ljungdahl, P.O. Asi1 is an inner nuclear membrane protein that restricts promoter access of two latent transcription factors. J. Cell Biol. 2006, 173, 695-707. [CrossRef] [PubMed]

64. Zargari, A.; Boban, M.; Heessen, S.; Andreasson, C.; Thyberg, J.; Ljungdahl, P.O. Inner nuclear membrane proteins Asi1, Asi2, and Asi3 function in concert to maintain the latent properties of transcription factors Stp1 and Stp2. J. Biol. Chem. 2007, 282, 594-605. [CrossRef] [PubMed]

65. Khmelinskii, A.; Blaszczak, E.; Pantazopoulou, M.; Fischer, B.; Omnus, D.J.; Le Dez, G.; Brossard, A.; Gunnarsson, A.; Barry, J.D.; Meurer, M.; et al. Protein quality control at the inner nuclear membrane. Nature 2014, 516, 410-413. [CrossRef] [PubMed]

66. Kota, J.; Gilstring, C.F.; Ljungdahl, P.O. Membrane chaperone Shr3 assists in folding amino acid permeases preventing precocious ERAD. J. Cell Biol. 2007, 176, 617-628. [CrossRef] [PubMed]

67. Ljungdahl, P.O.; Gimeno, C.J.; Styles, C.A.; Fink, G.R. SHR3: A novel component of the secretory pathway specifically required for localization of amino acid permeases in yeast. Cell 1992, 71,463-478. [CrossRef]

68. Dabas, N.; Morschhauser, J. A transcription factor regulatory cascade controls secreted aspartic protease expression in Candida albicans. Mol. Microbiol. 2008, 69, 586-602. [CrossRef]

69. Morschhauser, J. Nitrogen regulation of morphogenesis and protease secretion in Candida albicans. Int. J. Med. Microbiol. 2011, 301, 390-394. [CrossRef] 
70. Maidan, M.M.; De Rop, L.; Serneels, J.; Exler, S.; Rupp, S.; Tournu, H.; Thevelein, J.M.; Van Dijck, P. The G protein-coupled receptor Gpr1 and the Galpha protein Gpa2 act through the cAMP-protein kinase A pathway to induce morphogenesis in Candida albicans. Mol. Biol. Cell 2005, 16, 1971-1986. [CrossRef]

71. Miwa, T.; Takagi, Y.; Shinozaki, M.; Yun, C.W.; Schell, W.A.; Perfect, J.R.; Kumagai, H.; Tamaki, H. Gpr1, a putative G-proteincoupled receptor, regulates morphogenesis and hypha formation in the pathogenic fungus Candida albicans. Eukaryot. Cell 2004, 3 , 919-931. [CrossRef]

72. Van Ende, M.; Wijnants, S.; Van Dijck, P. Sugar Sensing and Signaling in Candida albicans and Candida glabrata. Front. Microbiol. 2019, 10, 99. [CrossRef] [PubMed]

73. Ballou, E.R.; Avelar, G.M.; Childers, D.S.; Mackie, J.; Bain, J.M.; Wagener, J.; Kastora, S.L.; Panea, M.D.; Hardison, S.E.; Walker, L.A.; et al. Lactate signalling regulates fungal beta-glucan masking and immune evasion. Nat. Microbiol. 2016, 2, 16238. [CrossRef]

74. Hogan, D.A.; Sundstrom, P. The Ras/cAMP/PKA signaling pathway and virulence in Candida albicans. Future Microbiol. 2009, 4, 1263-1270. [CrossRef] [PubMed]

75. Wang, Y. Fungal adenylyl cyclase acts as a signal sensor and integrator and plays a central role in interaction with bacteria. PLoS Pathog. 2013, 9, e1003612. [CrossRef]

76. Lu, P.; Takai, K.; Weaver, V.M.; Werb, Z. Extracellular matrix degradation and remodeling in development and disease. Cold Spring Harb. Perspect. Biol. 2011, 3, a005058. [CrossRef] [PubMed]

77. Pandhare, J.; Donald, S.P.; Cooper, S.K.; Phang, J.M. Regulation and function of proline oxidase under nutrient stress. J. Cell. Biochem. 2009, 107, 759-768. [CrossRef]

78. Taylor, B.N.; Staib, P.; Binder, A.; Biesemeier, A.; Sehnal, M.; Rollinghoff, M.; Morschhauser, J.; Schroppel, K. Profile of Candida albicans-secreted aspartic proteinase elicited during vaginal infection. Infect. Immun. 2005, 73, 1828-1835. [CrossRef]

79. Staib, P.; Kretschmar, M.; Nichterlein, T.; Hof, H.; Morschhauser, J. Differential activation of a Candida albicans virulence gene family during infection. Proc. Natl. Acad. Sci. USA 2000, 97, 6102-6107. [CrossRef]

80. Kretschmar, M.; Felk, A.; Staib, P.; Schaller, M.; Hess, D.; Callapina, M.; Morschhauser, J.; Schafer, W.; Korting, H.C.; Hof, H.; et al. Individual acid aspartic proteinases (Saps) 1-6 of Candida albicans are not essential for invasion and colonization of the gastrointestinal tract in mice. Microb. Pathog. 2002, 32, 61-70. [CrossRef] [PubMed]

81. Imbert, C.; Kauffmann-Lacroix, C.; Daniault, G.; Jacquemin, J.L.; Rodier, M.H. Effect of matrix metalloprotease inhibitors on the 95 kDa metallopeptidase of Candida albicans. J. Antimicrob. Chemother. 2002, 49, 1007-1010. [CrossRef]

82. Yuan, X.; Mitchell, B.M.; Wilhelmus, K.R. Expression of matrix metalloproteinases during experimental Candida albicans keratitis. Investig. Ophthalmol. Vis. Sci. 2009, 50, 737-742. [CrossRef]

83. Bi, X.; Henry, C.J. Plasma-free amino acid profiles are predictors of cancer and diabetes development. Nutr. Diabetes 2017, 7, e249. [CrossRef]

84. Toyoshima, K.; Nakamura, M.; Adachi, Y.; Imaizumi, A.; Hakamada, T.; Abe, Y.; Kaneko, E.; Takahashi, S.; Shimokado, K. Increased plasma proline concentrations are associated with sarcopenia in the elderly. PLoS ONE 2017, 12, e0185206. [CrossRef] [PubMed]

85. Logan, D.A. Partial purification and characterization of intracellular carboxypeptidase of Candida albicans. Exp. Mycol. 1987, 11, 115-121. [CrossRef]

86. Logan, D.A.; Naider, F.; Becker, J.M. Peptidases of Yeast and Filamentous Forms of Candida albicans. Exp. Mycol. 1983, 7, 116-126. [CrossRef]

87. El Moudni, B.; Rodier, M.H.; Barrault, C.; Ghazali, M.; Jacquemin, J.L. Purification and characterisation of a metallopeptidase of Candida albicans. J. Med. Microbiol. 1995, 43, 282-288. [CrossRef]

88. Rodier, M.-H.; El Moudni, B.; Ghazali, M.; Lacroix, C.; Jacquemin, J.-L. Electrophoretic Detection of Cytoplasmic Serine Proteinases (Gelatinases) in Candida albicans. Exp. Mycol. 1994, 18, 267-270. [CrossRef]

89. Chu, H.; Duan, Y.; Lang, S.; Jiang, L.; Wang, Y.; Llorente, C.; Liu, J.; Mogavero, S.; Bosques-Padilla, F.; Abraldes, J.G.; et al The Candida albicans exotoxin candidalysin promotes alcohol-associated liver disease. J. Hepatol. 2020, 72, 391-400. [CrossRef] [PubMed]

90. Kasper, L.; Konig, A.; Koenig, P.A.; Gresnigt, M.S.; Westman, J.; Drummond, R.A.; Lionakis, M.S.; Gross, O.; Ruland, J.; Naglik, J.R.; et al. The fungal peptide toxin Candidalysin activates the NLRP3 inflammasome and causes cytolysis in mononuclear phagocytes. Nat. Commun. 2018, 9, 4260. [CrossRef] [PubMed]

91. Moyes, D.L.; Wilson, D.; Richardson, J.P.; Mogavero, S.; Tang, S.X.; Wernecke, J.; Hofs, S.; Gratacap, R.L.; Robbins, J.; Runglall, M.; et al. Candidalysin is a fungal peptide toxin critical for mucosal infection. Nature 2016, 532, 64-68. [CrossRef]

92. Fukasawa, Y.; Tsuji, J.; Fu, S.C.; Tomii, K.; Horton, P.; Imai, K. MitoFates: Improved prediction of mitochondrial targeting sequences and their cleavage sites. Mol. Cell. Proteom. 2015, 14, 1113-1126. [CrossRef]

93. Han, T.L.; Cannon, R.D.; Gallo, S.M.; Villas-Bôas, S.G. A metabolomic study of the effect of Candida albicans glutamate dehydrogenase deletion on growth and morphogenesis. NPJ Biofilms Microbiomes 2019, 5, 13. [CrossRef]

94. Sickmann, A.; Reinders, J.; Wagner, Y.; Joppich, C.; Zahedi, R.; Meyer, H.E.; Schonfisch, B.; Perschil, I.; Chacinska, A.; Guiard, B.; et al. The proteome of Saccharomyces cerevisiae mitochondria. Proc. Natl. Acad. Sci. USA 2003, 100, 13207-13212. [CrossRef]

95. Mara, P.; Fragiadakis, G.S.; Gkountromichos, F.; Alexandraki, D. The pleiotropic effects of the glutamate dehydrogenase (GDH) pathway in Saccharomyces cerevisiae. Microb. Cell Factories 2018, 17, 170. [CrossRef] 
96. Schwencke, J.; Canut, H.; Flores, A. Simultaneous isolation of the yeast cytosol and well-preserved mitochondria with negligible contamination by vacuolar proteinases. FEBS Lett. 1983, 156, 274-280. [CrossRef]

97. Hollenberg, C.P.; Riks, W.F.; Borst, P. The glutamate dehydrogenases of yeast: Extra-mitochondrial enzymes. Biochim. Biophys. Acta 1970, 201, 13-19. [CrossRef]

98. Huh, W.K.; Falvo, J.V.; Gerke, L.C.; Carroll, A.S.; Howson, R.W.; Weissman, J.S.; O'Shea, E.K. Global analysis of protein localization in budding yeast. Nature 2003, 425, 686-691. [CrossRef]

99. Biswas, K.; Morschhauser, J. The Mep2p ammonium permease controls nitrogen starvation-induced filamentous growth in Candida albicans. Mol. Microbiol. 2005, 56, 649-669. [CrossRef]

100. Dabas, N.; Schneider, S.; Morschhauser, J. Mutational analysis of the Candida albicans ammonium permease Mep2p reveals residues required for ammonium transport and signaling. Eukaryot. Cell 2009, 8, 147-160. [CrossRef]

101. Palmieri, L.; Runswick, M.J.; Fiermonte, G.; Walker, J.E.; Palmieri, F. Yeast mitochondrial carriers: Bacterial expression, biochemical identification and metabolic significance. J. Bioenerg. Biomembr. 2000, 32, 67-77. [CrossRef]

102. Cavero, S.; Vozza, A.; del Arco, A.; Palmieri, L.; Villa, A.; Blanco, E.; Runswick, M.J.; Walker, J.E.; Cerdan, S.; Palmieri, F.; et al. Identification and metabolic role of the mitochondrial aspartate-glutamate transporter in Saccharomyces cerevisiae. Mol. Microbiol. 2003, 50, 1257-1269. [CrossRef]

103. Amoedo, N.D.; Punzi, G.; Obre, E.; Lacombe, D.; De Grassi, A.; Pierri, C.L.; Rossignol, R. AGC1/2, the mitochondrial aspartateglutamate carriers. Biochim. Biophys. Acta 2016, 1863, 2394-2412. [CrossRef]

104. Porcelli, V.; Vozza, A.; Calcagnile, V.; Gorgoglione, R.; Arrigoni, R.; Fontanesi, F.; Marobbio, C.M.T.; Castegna, A.; Palmieri, F.; Palmieri, L. Molecular identification and functional characterization of a novel glutamate transporter in yeast and plant mitochondria. Biochim. Biophys. Acta Bioenerg. 2018, 1859, 1249-1258. [CrossRef]

105. Palmieri, L.; Agrimi, G.; Runswick, M.J.; Fearnley, I.M.; Palmieri, F.; Walker, J.E. Identification in Saccharomyces cerevisiae of two isoforms of a novel mitochondrial transporter for 2-oxoadipate and 2-oxoglutarate. J. Biol. Chem. 2001, 276, 1916-1922. [CrossRef]

106. Palmieri, F.; Agrimi, G.; Blanco, E.; Castegna, A.; Di Noia, M.A.; Iacobazzi, V.; Lasorsa, F.M.; Marobbio, C.M.; Palmieri, L.; Scarcia, P.; et al. Identification of mitochondrial carriers in Saccharomyces cerevisiae by transport assay of reconstituted recombinant proteins. Biochim. Biophys. Acta 2006, 1757, 1249-1262. [CrossRef]

107. Tanner, J.J. Structural Biology of Proline Catabolic Enzymes. Antioxid. Redox Signal. 2019, 30, 650-673. [CrossRef]

108. Liu, L.K.; Becker, D.F.; Tanner, J.J. Structure, function, and mechanism of proline utilization A (PutA). Arch. Biochem. Biophys. 2017, 632, 142-157. [CrossRef]

109. Christgen, S.L.; Becker, D.F. Role of Proline in Pathogen and Host Interactions. Antioxid. Redox Signal. 2018, 30, 683-709. [CrossRef]

110. Phang, J.M. Proline Metabolism in Cell Regulation and Cancer Biology: Recent Advances and Hypotheses. Antioxid. Redox Signal. 2019, 30, 635-649. [CrossRef]

111. Nishimura, A.; Nasuno, R.; Takagi, H. The proline metabolism intermediate Delta1-pyrroline-5-carboxylate directly inhibits the mitochondrial respiration in budding yeast. FEBS Lett. 2012, 586, 2411-2416. [CrossRef]

112. Deuschle, K.; Funck, D.; Forlani, G.; Stransky, H.; Biehl, A.; Leister, D.; van der Graaff, E.; Kunze, R.; Frommer, W.B. The role of [Delta]1-pyrroline-5-carboxylate dehydrogenase in proline degradation. Plant Cell 2004, 16, 3413-3425. [CrossRef]

113. Miller, G.; Honig, A.; Stein, H.; Suzuki, N.; Mittler, R.; Zilberstein, A. Unraveling delta1-pyrroline-5-carboxylate-proline cycle in plants by uncoupled expression of proline oxidation enzymes. J. Biol. Chem. 2009, 284, 26482-26492. [CrossRef]

114. Cooper, T. Nitrogen metabolism in Saccharomyces cerevisiae. In The Molecular Biology of the Yeast Saccharomyces: Metabolism and Gene Expression; Strathern, J.N., Jones, E.W., Broach, J.R., Eds.; Cold Spring Harbor Laboratory: Cold Spring Harbor, NY, USA, 1982; Volume 2, pp. 39-100.

115. Lagree, K.; Woolford, C.A.; Huang, M.Y.; May, G.; McManus, C.J.; Solis, N.V.; Filler, S.G.; Mitchell, A.P. Roles of Candida albicans Mig1 and Mig2 in glucose repression, pathogenicity traits, and SNF1 essentiality. PLoS Genet. 2020, 16, e1008582. [CrossRef]

116. Rodaki, A.; Bohovych, I.M.; Enjalbert, B.; Young, T.; Odds, F.C.; Gow, N.A.; Brown, A.J. Glucose promotes stress resistance in the fungal pathogen Candida albicans. Mol. Biol. Cell 2009, 20, 4845-4855. [CrossRef]

117. Vemuri, G.N.; Eiteman, M.A.; McEwen, J.E.; Olsson, L.; Nielsen, J. Increasing NADH oxidation reduces overflow metabolism in Saccharomyces cerevisiae. Proc. Natl. Acad. Sci. USA 2007, 104, 2402-2407. [CrossRef]

118. Grahl, N.; Demers, E.G.; Lindsay, A.K.; Harty, C.E.; Willger, S.D.; Piispanen, A.E.; Hogan, D.A. Mitochondrial Activity and Cyr1 Are Key Regulators of Ras1 Activation of C. albicans Virulence Pathways. PLoS Pathog. 2015, 11, e1005133. [CrossRef]

119. Fernandes, T.R.; Segorbe, D.; Prusky, D.; Di Pietro, A. How alkalinization drives fungal pathogenicity. PLoS Pathog. 2017, 13, e1006621. [CrossRef]

120. Vylkova, S. Environmental pH modulation by pathogenic fungi as a strategy to conquer the host. PLoS Pathog. 2017, 13, e1006149. [CrossRef]

121. Huang, J.-C.; Shang, C. Air Stripping. In Advanced Physicochemical Treatment Processes; Humana Press: Totowa, NJ, USA, 2006; pp. 47-79. [CrossRef]

122. Westman, J.; Moran, G.; Mogavero, S.; Hube, B.; Grinstein, S. Candida albicans Hyphal Expansion Causes Phagosomal Membrane Damage and Luminal Alkalinization. mBio 2018, 9, e01226-18. [CrossRef]

123. Naseem, S.; Araya, E.; Konopka, J.B. Hyphal growth in Candida albicans does not require induction of hyphal-specific gene expression. Mol. Biol. Cell 2015, 26, 1174-1187. [CrossRef] [PubMed] 
124. Rane, H.S.; Hayek, S.R.; Frye, J.E.; Abeyta, E.L.; Bernardo, S.M.; Parra, K.J.; Lee, S.A. Candida albicans Pma1p Contributes to Growth, pH Homeostasis, and Hyphal Formation. Front. Microbiol. 2019, 10, 1012. [CrossRef] [PubMed]

125. Danhof, H.A.; Lorenz, M.C. The Candida albicans ATO Gene Family Promotes Neutralization of the Macrophage Phagolysosome. Infect. Immun. 2015, 83, 4416-4426. [CrossRef]

126. Cueto-Rojas, H.F.; Milne, N.; van Helmond, W.; Pieterse, M.M.; van Maris, A.J.A.; Daran, J.M.; Wahl, S.A. Membrane potential independent transport of NH3 in the absence of ammonium permeases in Saccharomyces cerevisiae. BMC Syst. Biol. 2017, 11, 49. [CrossRef]

127. Ip, Y.K.; Chew, S.F. Ammonia production, excretion, toxicity, and defense in fish: A review. Front. Physiol. 2010, 1, 134. [CrossRef]

128. Antonenko, Y.N.; Pohl, P.; Denisov, G.A. Permeation of ammonia across bilayer lipid membranes studied by ammonium ion selective microelectrodes. Biophys. J. 1997, 72, 2187-2195. [CrossRef]

129. Velasco, I.; Tenreiro, S.; Calderon, I.L.; Andre, B. Saccharomyces cerevisiae Aqr1 Is an Internal-Membrane Transporter Involved in Excretion of Amino Acids. Eukaryot. Cell 2004, 3, 1492-1503. [CrossRef]

130. Land, G.A.; McDonald, W.C.; Stjernholm, R.L.; Friedman, T.L. Factors affecting filamentation in Candida albicans: Relationship of the uptake and distribution of proline to morphogenesis. Infect. Immun. 1975, 11, 1014-1023. [CrossRef]

131. Dabrowa, N.; Taxer, S.S.; Howard, D.H. Germination of Candida albicans induced by proline. Infect. Immun. 1976, 13, 830-835. [CrossRef] [PubMed]

132. Dabrowa, N.; Howard, D.H. Proline uptake in Candida albicans. Microbiology 1981, 127, 391-397. [CrossRef]

133. Holmes, A.R.; Shepherd, M.G. Proline-induced germ-tube formation in Candida albicans: Role of proline uptake and nitrogen metabolism. Microbiology 1987, 133, 3219-3228. [CrossRef]

134. Zhang, L.; Becker, D.F. Connecting proline metabolism and signaling pathways in plant senescence. Front. Plant Sci. 2015, 6, 552. [CrossRef] [PubMed]

135. Liang, X.; Zhang, L.; Natarajan, S.K.; Becker, D.F. Proline mechanisms of stress survival. Antioxid. Redox Signal. 2013, 19, 998-1011. [CrossRef] [PubMed]

136. Ohsumi, Y.; Kitamoto, K.; Anraku, Y. Changes induced in the permeability barrier of the yeast plasma membrane by cupric ion. $J$. Bacteriol. 1988, 170, 2676-2682. [CrossRef]

137. Kitamoto, K.; Yoshizawa, K.; Ohsumi, Y.; Anraku, Y. Dynamic aspects of vacuolar and cytosolic amino acid pools of Saccharomyces cerevisiae. J. Bacteriol. 1988, 170, 2683-2686. [CrossRef]

138. Singh, R.K.; Rinehart, C.A.; Kim, J.P.; Tolleson-Rinehart, S.; Lawing, L.F.; Kaufman, D.G.; Siegal, G.P. Tumor cell invasion of basement membrane in vitro is regulated by amino acids. Cancer Investig. 1996, 14, 6-18. [CrossRef]

139. Pasini, E.; Aquilani, R.; Dioguardi, F.S. Amino acids: Chemistry and metabolism in normal and hypercatabolic states. Am. J. Cardiol. 2004, 93, 3A-5A. [CrossRef] [PubMed]

140. Dioguardi, F.S. Wasting and the substrate-to-energy controlled pathway: A role for insulin resistance and amino acids. Am. J. Cardiol. 2004, 93, 6A-12A. [CrossRef] 